\title{
Ethylene-Responsive AP2/ERF Transcription Factor MACD1 Participates in Phytotoxin-Triggered Programmed Cell Death
}

\author{
Keisuke Mase, ${ }^{1}$ Nobuaki Ishihama, ${ }^{1}$ Hitoshi Mori, ${ }^{2}$ Hideki Takahashi, ${ }^{3}$ Hironori Kaminaka, ${ }^{4}$ \\ Motoichiro Kodama, ${ }^{5}$ and Hirofumi Yoshioka ${ }^{1}$ \\ ${ }^{1}$ Laboratory of Defense in Plant-Pathogen Interactions, and ${ }^{2}$ Developmental Regulation Laboratory, Graduate School of \\ Bioagricultural Sciences, Nagoya University, Chikusa, Nagoya 464-8601, Japan; ${ }^{3}$ Graduate School of Agricultural Science, \\ Tohoku University, Sendai 981-8555, Japan; ${ }^{4}$ Laboratory of Plant Molecular Biology, and ${ }^{5}$ Laboratory of Plant Pathology, \\ Faculty of Agriculture, Tottori University, 4-101 Koyama-Minami, Tottori 680-8553, Japan
}

Submitted 1 November 2012. Accepted 11 April 2013.

To investigate plant programmed cell death (PCD), we developed the model system using phytotoxin AAL, which is produced by necrotrophic pathogen Alternaria alternata f. sp. lycopersici, and AAL-sensitive Nicotiana umbratica. We previously reported that ethylene (ET) signaling plays a pivotal role in AAL-triggered cell death (ACD). However, downstream signaling of ET to ACD remains unclear. Here, we show that the modulator of $\mathrm{AAL}$ cell death 1 (MACD1), which is an APETALA2/ET response factor (ERF) transcription factor, participates in ACD and acts downstream of ET signaling during ACD. MACD1 is a transcriptional activator and MACD1 overexpression plants showed earlier ACD induction than control plants, suggesting that MACD1 positively regulates factors affecting cell death. To investigate the role of MACD1 in PCD, we used Arabidopsis thaliana and a structural analog of AAL, fumonisin B1 (FB1). FB1-triggered cell death was compromised in ET signaling and erf102 mutants. The loh2 mutants showed sensitivity to AAL, and the loh2-1/erf102 double mutant compromised ACD, indicating that ERF102 also participates in ACD. To investigate the PCD-associated genes regulated by ERF102, we compared our microarray data using ERF102 overexpression plants with the database of upregulated genes by AAL treatment in loh2 mutants, and found genes under the control of ERF102 in ACD.

Programmed cell death (PCD) is essential for plant development and immunity. Localized PCD is associated with hypersensitive response (HR), which is a constituent of a successful plant innate immune response. Rapid and localized PCD, known as HR cell death, is induced at the infection site to prevent growth and spread of pathogens into healthy tissues (Greenberg 1997). This response is initiated by direct or in-

Current address for N. Ishihama: RIKEN Plant Science Center, Suehirocho 1-7-22 Tsurumi-ku, Yokohama 230-0045, Japan.

Corresponding author: H. Yoshioka; E-mail: hyoshiok@agr.nagoya-u.ac.jp

* The $\boldsymbol{e}$-Xtra logo stands for "electronic extra" and indicates that 10 supplementary figures, four supplementary tables, one supplementary dataset, and supplementary materials and methods are published online. Also, Figures $1,3,4,5,7$, and 8 appear in color online.

C 2013 The American Phytopathological Society direct recognition of a pathogen avirulence $(A v r)$ factor by a plant resistance $(R)$ gene product and is controlled by multiple signal transduction pathways (Moffett 2009). Some pathogenassociated molecular patterns, such as INF1 elicitin (Kamoun et al. 2003), xylanase (Bailey et al. 1990), and AvrXa21 (Lee et al. 2009), also induce HR cell death. The HR cell death signaling pathway has been studied genetically and biochemically but the signaling pathway of plant PCD is not fully understood.

Host-selective toxins (HST) are effectors produced by some necrotrophic pathogenic fungi that typically confer the ability to cause disease (Markham and Hille 2001; Walton 1996). Plant cells exposed to phytotoxins produced by necrotrophic pathogens induce cell death associated with morphological markers indicative of PCD (Gilchrist 1998; Greenberg and Yao 2004). Victorin, a phytotoxin produced by Cochliobolus victoriae, triggers $\mathrm{PCD}$ in oat cultivars carrying the dominant $\mathrm{Vb}$ allele (Wolpert et al. 1985). Victorin also induces cell death in Arabidopsis thaliana carrying LOV1, which is a gene that confers disease susceptibility and, paradoxically, is a member of the coiled-coil nucleotide-binding site leucine-rich repeat $R$ family (Lorang et al. 2007). Thioredoxin-h5 (TRX-h5) is also genetically required for victorin sensitivity in Arabidopsis thaliana (Sweat and Wolpert 2007). Victorin was recently shown to bind to TRX-h5 and inhibit its activity (Lorang et al. 2012). LOV1 guards the inhibition of TRX-h5 by victorin and elicits a resistance-like response, including cell death (Lorang et al. 2012). AAL is a phytotoxin produced by Alternaria alternata f. sp. lycopersici (Wang et al. 1996) that causes disease in its sensitive natural host tomato and some Nicotiana spp. lacking the Alternaria stem canker gene 1 (Asc-1) (Brandwagt et al. 2000, 2001).

Some phytotoxin-induced PCD requires an ethylene (ET)dependent signaling pathway. ET inhibitors aminooxyacetic acid (inhibitor of ET biosynthesis) and silver thiosulfate (inhibitor of ET action) also give marked protection against victorin-induced leaf symptoms in oat leaves (Navarre and Wolpert 1999). Slight attenuation of LOVI-mediated victorin sensitivity occurs in the Arabidopsis thaliana ein2 mutant (Lorang et al. 2007). The never ripe mutants of tomato, which affect ET perception, show less cell death symptom response to AAL than wild-type tomato (Moore et al. 1999; Zhang et al. 2011). Co-treatment of asc/asc leaflets with AAL and ET inhibitors markedly reduces cell death symptoms (Moussatos et al. 1994). AAL-triggered cell death (ACD) in AAL-sensitive N. umbratica requires the ET dependent signaling pathway (Mase et al. 2012). 
These studies indicate that the ET-dependent signal pathway contributes to phytotoxin-induced PCD. However, downstream of ET-dependent signaling in PCD is not well understood. Identification of ET downstream components will help us understand how ET signaling participates in plant PCD.

ET-insensitive 3 (EIN3) is a plant-specific nuclear transcription factor that initiates downstream transcriptional cascades for ET responses in A. thaliana (Alonso et al. 2003; Solano et al. 1998; Yanagisawa et al. 2003). EIN3 is a short-lived protein that is degraded by a ubiquitin/26S proteasome pathway in the absence of ET. Genetic and biochemical studies showed that EIN3 proteolysis is mediated by F-box proteins EIN3-binding F-box 1 and 2 (EBF1 and EBF2) (Gagne et al. 2004; Guo and Ecker 2003; Potuschak et al. 2003). ET-insensitive 2 (EIN2) is required to degrade EBF1 and EBF2 to accumulate EIN3 and ET-insensitive-like1 (EIL1) (An et al. 2010). Stabilized EIN3 and EIL activate the expression of targets, such as ET response factor 1 (ERFl) transcription factor, which initiates a transcriptional cascade that results in activation and repression of hundreds of genes (Solano et al. 1998). ERF1 belongs to the APETALA2 (AP2)/ERF family of transcription factors. The AP2/ERF family is only present in the plant kingdom and is characterized by the presence of a highly conserved DNAbinding domain called the AP2 domain (Riechmann et al. 1998). The AP2/ERF family can be divided into five subfamilies from the number and sequences of their AP2 domains (Sakuma et al. 2002). The ERF subfamily has a single AP2 domain and shows DNA-binding activity. Some ERF proteins bind specifically to the GCC-box (AGCCGCC), which is an ET-responsive element. The binding of ERF proteins to the GCC-box regulates ET-responsive transcription (Fujimoto et al. 2000; Ohme-Takagi and Shinshi 1995).

In a previous study, we developed a model system using AAL and N. umbratica to analyze plant PCD (Mase et al. 2012). AAL is an HST and is a sphinganine-analog mycotoxin (SAM). SAM structurally resemble sphinganine, an intermediate of sphingolipid biosynthesis (Wang et al. 1996). AAL causes PCD in its sensitive plants by inhibition of ceramide biosynthesis (Gilchrist 1997; Spassieva et al. 2002; Wang et al. 1996). We showed that mitogen-activated protein kinase-mediated ET production is required for ACD in N. umbratica (Mase et al. 2012), and that plants with silenced ET signaling components showed depression of ACD, suggesting that ET signaling has pivotal roles in ACD. In this study, we investigated key factors downstream of ET signaling pathways in ACD. Here, we report that the modulator of AAL cell death 1 (MACD1), which is an AP2/ERF transcription factor, participates in ACD. A. thaliana MACD1 ortholog ERF102 also has an important role in the structural analog of AAL, fumonisin B1 (FB1)-triggered cell death (FCD), as well as ACD, in an AAL-sensitive Arabidopsis mutant. Also, we identified genes that act downstream of ERF102 in ACD by using microarray analysis.

\section{RESULTS}

\section{Virus-induced gene silencing (VIGS) of $M A C D 1$ compromised ACD.}

To investigate unknown downstream components of ET-signaling pathways in ACD, we performed VIGS analysis based on the Tobacco rattle virus (TRV) vector in $N$. umbratica (Ratcliff et al. 2001). First, to identify the MACD genes, we knocked down ET-responsive $N$. tabacum ERF homologs in $N$. umbratica, which were reported as ET-responsive element-binding protein-1 (EREBP-1), EREBP-2, and EREBP-4 (NtERF1, NtERF2, and NtERF4) (Ohme-Takagi and Shinshi 1995) and NtERF5 (Fischer and Dröge-Laser 2004). We isolated cDNA fragments of NuERF1 (AB747101), NuERF2 (AB747102),
NuERF4 (AB747103), and NuERF5 (AB747104) from the $N$. umbratica cDNA library by using polymerase chain reaction (PCR) with primer design based on the NtERF sequences. To avoid off-target effects by VIGS, the fragments, except the AP2/ERF domain, were used for the VIGS vector (Supplementary Fig. S1A). The expression level of $N u E R F$ was markedly reduced in each TRV:NuERF-infected plant compared with the TRV control plants. ACD was compromised in NuERF4silenced plants but not in other $N u E R F$-silenced plants (Fig. 1A). The mRNA levels of $N u E R F$ genes $N u E R F 1, N u E R F 2$, and NuERF5 showed no noteworthy differences between TRV:NuERF4 plants and TRV control plants, suggesting that $N u E R F 4$ silencing does not affect the expression levels of at least three $N u E R F$ genes. To quantify cell death, we measured the ion leakage of AAL-treated plants (Fig. 1B). AAL-induced ion leakage was suppressed in NuERF4-silenced plants. We designated NuERF4 as MACD1 from these results.

\section{MACD1 acts downstream of ET signaling in ACD.}

We examined whether $M A C D 1$ expression is influenced by ET during ACD. NuERF1, the NtERF1 homolog, was used as a positive control of the ET-inducible gene in $N$. umbratica (Fig. 2A, left). The gene tobacco EIN3-like (TEIL) and its related genes have been implicated in ET signaling (Hibi et al. 2007; Kosugi and Ohashi 2000; Rieu et al. 2003). We previously showed that ACD is compromised in TEIL-silenced leaves (Mase et al. 2012). ET-induced $N u E R F 1$ expression was suppressed in TRV:TEIL (Fig. 2A, right). MACD1 was induced by ET treatment (Fig. 2B), indicating that MACD1 is also an ET-inducible gene.

We checked the expression profiles of MACDI in ACD. MACD1 peaked at $36 \mathrm{~h}$ after AAL treatment of $N$. umbratica (Fig. 2C). ET accumulated in ACD at 24 to $48 \mathrm{~h}$ after AAL treatment (Mase et al. 2012); possibly, MACDl expression is induced by ET in response to AAL. To confirm this possibility, we examined $M A C D 1$ expression in $T E I L$-silenced plants. The expression level of MACDI by AAL was suppressed in TRV: TEIL plants (Fig. 2D), indicating that MACDl is downstream of ET signaling during ACD.

\section{MACD1 positively regulates factors participating in cell death development.}

The predicted protein of MACD1 does not contain the ERFassociated amphiphilic repression (EAR) motif (L/FDLNL/F [x] P), which acts as a repression domain and converts transcriptional activators into strong repressors when fused with DNA-binding proteins (Ohta et al. 2001). To determine the transactivation activity of MACD1 in plants, we used a yeast GAL4 system-modified and Agrobacterium-mediated transient assay system (Ishihama et al. 2011). The $\beta$-glucuronidase (GUS) reporter gene containing an intron to avoid expression in Agrobacterium was fused under the control of a synthetic promoter consisting of the minimal Cauliflower mosaic virus $35 \mathrm{~S}$ promoter and the GAL4 upstream activation sequence (GAL4UAS) (Fig. 3A). The GAL4 DNA binding domain (GAL4DBD) that was fused to the activation domain of herpes simplex virus VP16 (GAL4DBD-VP16) was used as a positive control to activate the GAL4UAS-GUS reporter gene (Fig. 3A and B). We replaced VP16 with MACD1 and eventually constructed GAL4DBD-MACD1 chimera DNA (Fig. 3A). If MACD1 is a transcriptional activator, the GUS reporter gene is induced by co-expression of GAL4DBD-MACD1 and reporter construct in $N$. benthamiana plants. GAL4DBD-MACD1 showed higher GUS activities compared with GAL4DBD (Fig. 3B), indicating that MACD1 is a positive regulator of transcription.

Some ERF transcription factors most likely function by binding to cognate GCC-box cis-elements in the promoter region 
of target genes (Fujimoto et al. 2000; Ohme-Takagi and Shinshi 1995). To examine the binding activity of MACD1 with GCCbox, we modified the Agrobacterium-mediated transient assay system described above. We replaced GAL4UAS with GCC or mutated GCC (mGCC) elements in reporter plasmids (Fig. 3C). If MACD1 has the binding activity with GCC-box, GUS activity is detected by MACD1 and reporter co-expression. MACD1 was transiently expressed by using Agrobacterium tumefaciens infiltration (agroinfiltration) in N. benthamiana

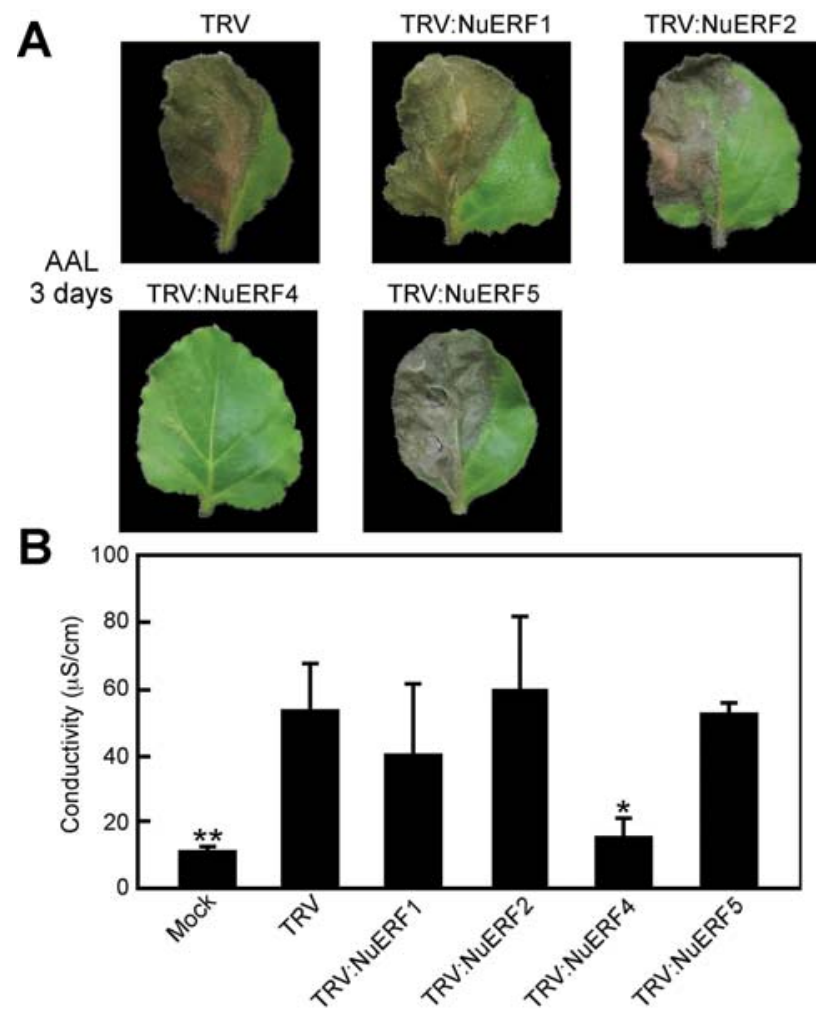

Fig. 1. Effects of silencing $N u E R F$ genes on AAL-triggered cell death (ACD). A, Silencing NuERF4 compromised ACD in Nicotiana umbratica. B, ACD quantified by ion leakage from AAL-treated leaves. Data are means \pm standard deviations from at least three independent experiments. Data underwent a Student's $t$ test: ** and * indicate $P<0.01$ and 0.05 , respectively, versus Tobacco rattle virus (TRV) control plants. plants. Transient MACD1 expression raised the activity of the co-transfected synthetic promoter with GCC elements but not MACD1 with mutated GCC (mGCC) (Fig. 3C and D), suggesting that MACD1 binds to the GCC-box.

To investigate the subcellular localization of MACD1, MACD1 was fused to green fluorescent protein (GFP) in the $\mathrm{N}$ terminal or $\mathrm{C}$ terminal, because it is possible that GFP position has an effect on the subcellular localization. MACD1-GFP and GFP-MACD1 were expressed transiently in $N$. benthamiana by agroinfiltration. Stain 4',6-diamidino-2-phenylindole (DAPI) was used to indicate nuclear localization (Fig. 3E). MACD1GFP or GFP-MACD1 was found in the nucleus. These results show that MACD1 has features of the AP2/ERF family.

To examine the function of MACD1 in ACD, N. umbratica leaves were inoculated with $A$. tumefaciens containing MACD1 or GUS as a control. Necrotic lesions were not observed in MACD1 overexpression (OE) plants and GUS OE control plants (Fig. 4A to C), indicating that MACD1 OE is not sufficient to induce cell death. $N$. umbratica leaves were treated with AAL at $24 \mathrm{~h}$ after agroinfiltration, and ACD emerged more rapidly in MACD1 OE plants than in GUS OE plants (Fig. 4D). AALinduced ion leakage increased in MACD1 OE plants (Fig. 4E). These results suggest that MACD1 positively regulates factors participating in cell death development.

\section{ERF102 participates}

in FCD cell death in Arabidopsis thaliana.

To further investigate ET signaling in plant PCD, we used a model system using FB1 and Arabidopsis thaliana. FB1 is an AAL structural analog, is a SAM, and induces PCD by disturbance in ceramide biosynthesis (Gilchrist 1997; Wang et al. 1996). ET signaling appears to participate in FCD in A. thaliana protoplasts (Asai et al. 2000). Using A. thaliana instead of $N$. umbratica for the analysis has the following advantages: we can use the completed A. thaliana genome sequence (Arabidopsis Genome Initiative 2000), well-developed mutants lines, and well-established microarray analysis. First, to examine whether the ET signal pathway is required for FCD in A. thaliana, etrl-1 (Chang et al. 1993) and ein3 (Solano et al. 1998) mutants and ET receptor mutants and ET signaling mutants, respectively, were treated with FB1. Reduction of FCD and FB1-induced ion leakage were observed in etrl-1 and ein3 mutants (Fig. 5A and B), indicating that the ET signaling pathway has important roles in FCD.
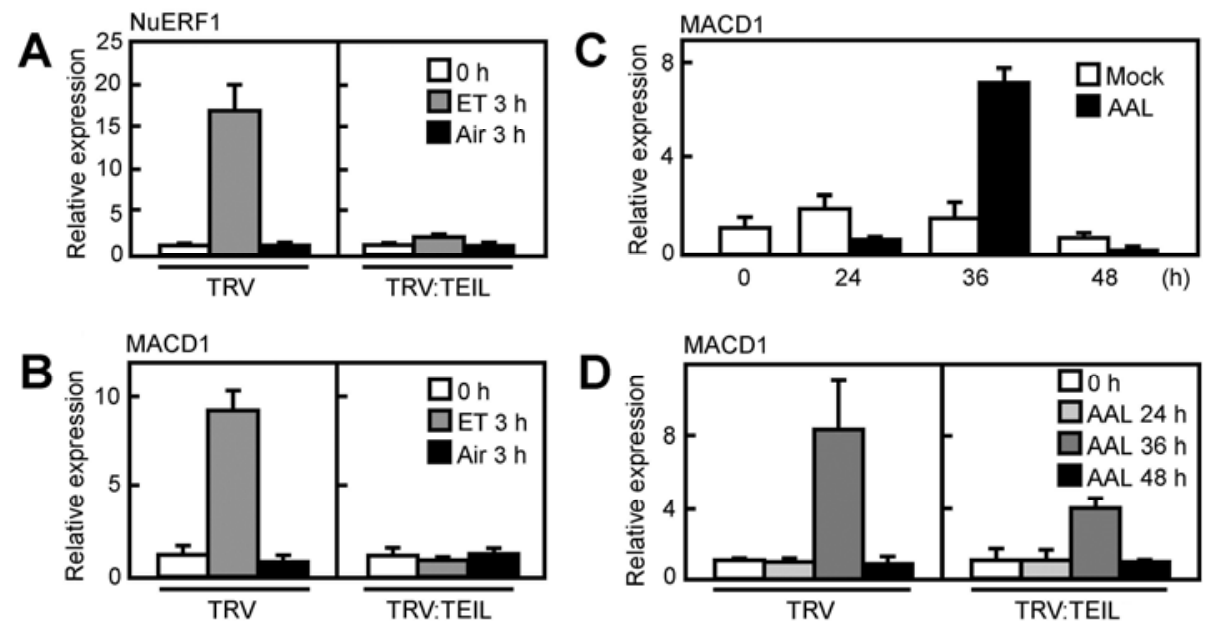

Fig. 2. Transcript accumulation of modulator of AAL cell death 1 (MACD1) in response to ethylene (ET) and AAL. mRNA accumulation of A, NuERF1 and B, MACD1 after ET treatment in Tobacco rattle virus (TRV) control plants or TRV:tobacco EIN3-like (TEIL) plants. EF-1 $\alpha$ was used as an internal standard. Data are means \pm standard deviations (SD) from three experiments. Expression profiles of MACD1 after AAL treatment in C, Nicotiana umbratica and D, MACD1 after AAL treatment in TRV control plants or TRV:TEIL plants, $E F-1 \alpha$ was used as an internal standard. Data are means \pm SD from three experiments. 
To explore the MACD1 homologs in A. thaliana, multiple alignment analyses were done using amino acid sequences of the AP2/ERF domain in A. thaliana, N. umbratica, N. tabacum, Solanum tuberosum, and $S$. lycopersicum (Supplementary Fig. S2). NuERF4 encoded a protein that was similar to ERF102 (previously called ERF5; At5g47230), ERF103 (previously called ERF6; At4g17490), ERF104 (At5g61600), and ERF105 (At5g51190), which are classified into A. thaliana ERF group IX subfamily (Nakano et al. 2006). A. thaliana T-DNA insertion mutants for ERF102 (erf102; SALK_076967) and ERF103 (erf103; SALK_087356) were obtained from the SALK T-DNA collection (Supplementary Fig. S3).

To examine the effects of erf102 and erflo3 mutation on FCD, we treated erf102 and erflo3 mutants with FB1. FCD was significantly reduced in the erf102 mutant (Fig. 5C).
ERF104 interacts with MPK6 and is a vital regulator of basal immunity (Bethke et al. 2009). In our study, erf104 mutant showed normal FCD development (Fig. 5C). FB1-induced ion leakage was also significantly reduced in the erf102 mutant but scarcely in erf103 mutant (Fig. 5D). We examined whether ERF102 rescues the FCD depression phenotype in the erf102 mutant. Expression of ERF102 from the 35S promoter complemented the erf102-mediated suppression of FCD (Supplementary Fig. S4). These results suggest that ERF102 participates in FCD and is an MACD1 ortholog in A. thaliana.

ERF102 (ERF5) and ERF103 (ERF6) are known to have redundant roles in plant defense responses against various pathogens (Moffat et al. 2012; Son et al. 2012). To further investigate the roles of ERF102 and ERF103 in FCD, we tested the erf102/erf103 double mutant (Moffat et al. 2012). The

A

Effector 35 S promoter-GAL4DBD MACD1-NOS

\section{Reporter}

6xGAL4UAS $-\triangle 35 S$ - GUSint NOS

Reference

35 S promoter- LUCint NOS

\section{C}

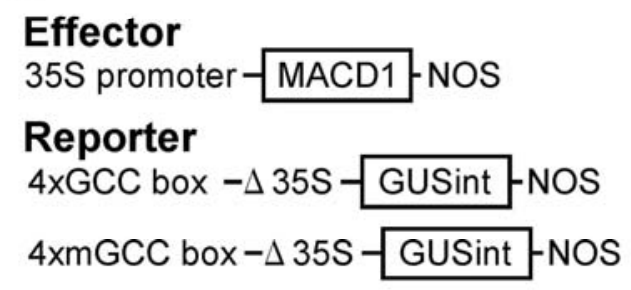

Reference 355 promoter- LUCint NOS

E

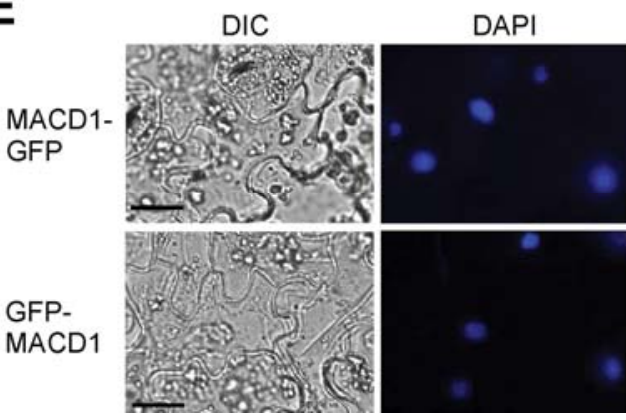

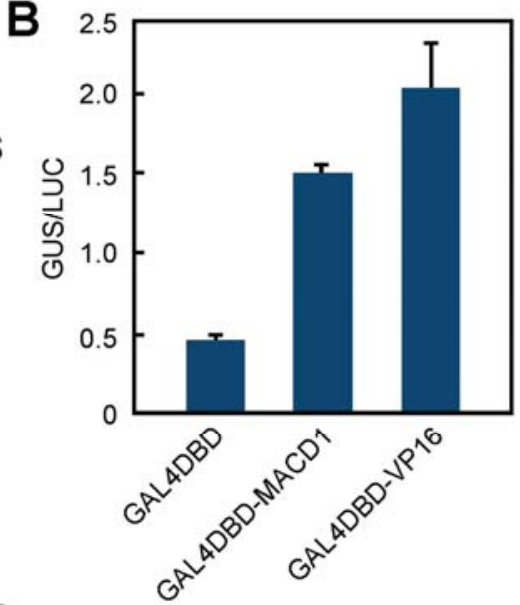
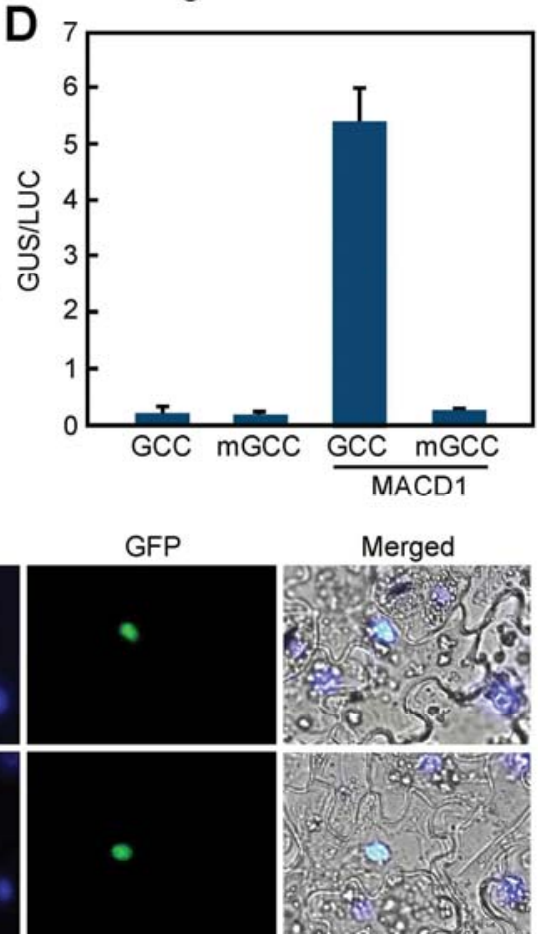

Fig. 3. Characterization of modulator of AAL cell death 1 (MACD1). A, Schematic diagram of effector, reporter, and reference plasmids used in transient assays to estimate MACD1 transcriptional activity. B, Transactivation of the $\beta$-glucuronidase (GUS) gene by GAL4DBD-MACD1 in Nicotiana benthamiana leaves. Total proteins were extracted from leaves coinfiltrated with Agrobacterium-containing reporter plasmids, effector plasmids, or reference plasmids. GUS activity was normalized to luciferase (LUC) activity. C, Schematic diagram of effector, reporter, and reference plasmids used in transient assays for evaluation of MACD1 GCC-box-mediated gene expression. D, MACD1 can transactivate GCC-box-mediated gene expression in N. benthamiana leaves. Total proteins were extracted from leaves coinfiltrated with Agrobacterium-containing reporter plasmids, effector plasmids, or reference plasmids. GUS activity was normalized to LUC activity. E, Subcellular localization of MACD1 in N. benthamiana epidermal cells. N. benthamiana leaves were transformed with MACD1-green fluorescent protein (GFP) and GFP-MACD1 by agroinfiltration. DAPI = 4',6-diamidino-2-phenylindole; DIC $=$ differential interference contrast; bars $=20 \mu \mathrm{m}$. 
erf102/erf103 double mutant showed lower conductivity than the erf102 single mutant (Fig. 5E). Although the erf103 mutant did not compromise FCD clearly, it is possible that ERF103 also contributes to FCD induction.

\section{ERF102 acts downstream of ET signaling during FCD.}

To examine whether ERF102 acts downstream of ET signaling during FCD, we checked the expression profiles of ERF102. ERF1 (At3g23240) was used as a positive control for

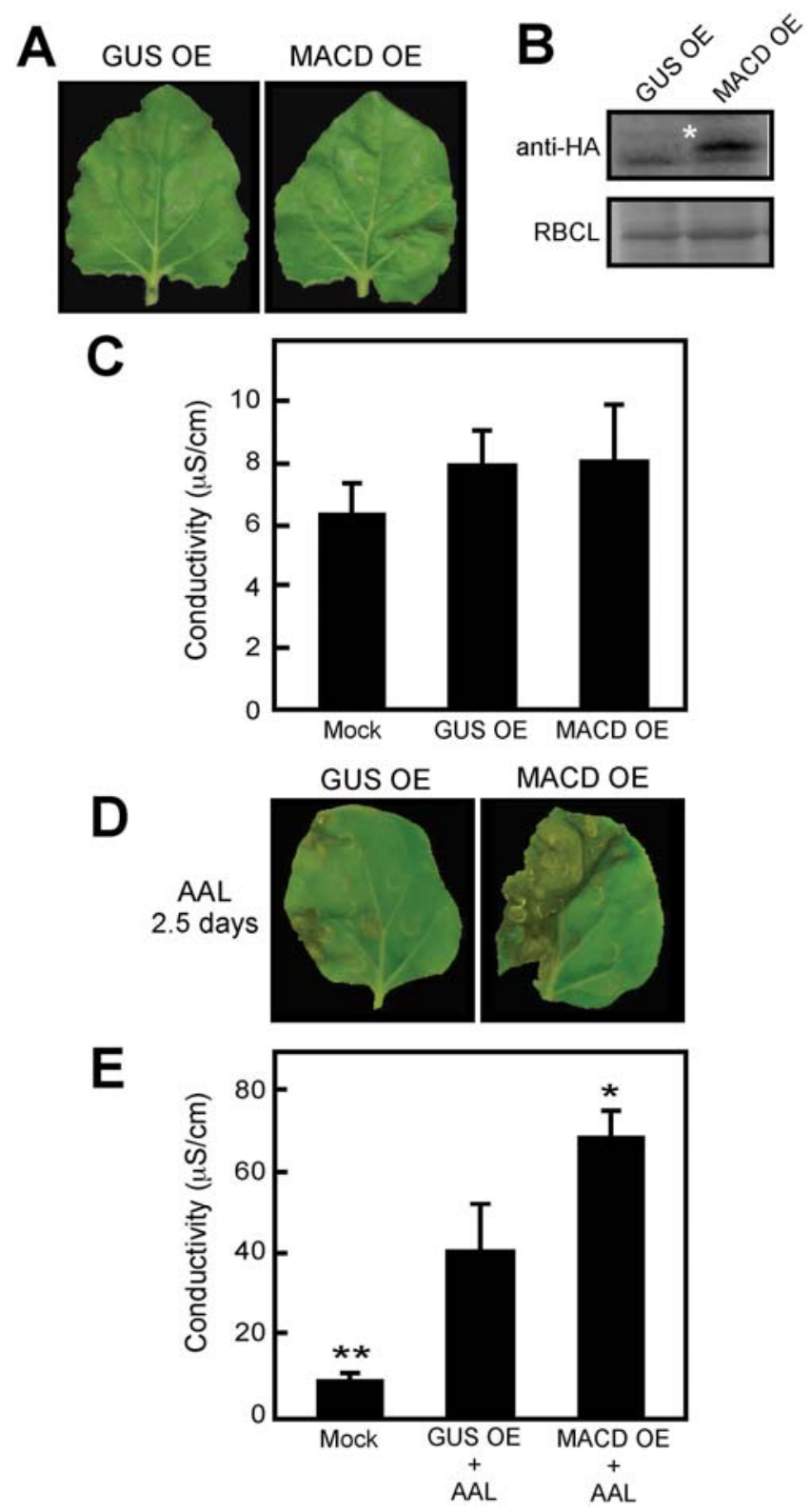

Fig. 4. AAL-triggered cell death (ACD) emerges more rapidly in modulator of AAL cell death 1 (MACD1) overexpression (OE) plants. A, Effects of MACD1 OE by agroinfiltration in Nicotiana umbratica. B, Transient expression of MACD1 protein in N. umbratica leaves. Proteins were analyzed by immunoblotting using anti- hemagglutinin (HA) antibody. Protein loads were monitored by Coomassie Brilliant Blue (CBB) staining of the bands corresponding to ribulose-1,5-bisphosphate carboxylase large subunit (RBCL). Asterisk indicates the pertinent band of MACD1. C, Cell death shown in A quantified by ion leakage from infiltrated-leaves. Data are means \pm standard deviations (SD) from at least three independent experiments. D, Effects of MACD1 OE on ACD. Leaves were treated with AAL at $24 \mathrm{~h}$ after agroinfiltration. E, ACD shown in D quantified by ion leakage from AAL-treated leaves. Data are means \pm SD from at least three independent experiments: $* *$ and $*$ indicate $P<0.01$ and 0.05 , respectively, versus $\beta$-glucuronidase (GUS) $\mathrm{OE}$ control plants. the ET-inducible gene (Fig. 6A, left). ET-dependent induction of ERF1 was suppressed in etr1-1 and ein 3 mutants (Fig. 6A, middle, right). ERF102 was also an ET-inducible gene (Fig. 6B). The expressions of ERF1 and ERF102 were induced by FB1 treatment (Fig. 6C, left and D, left). However, FB1inducible expression of ERF1 and ERF102 was suppressed in etrl-1 and ein 3 mutants (Fig. 6C, middle, right and 6D, middle, right). These results indicate that ERF102 acts downstream of ET signaling during FCD.

\section{ERF102 positively regulates factors participating} in cell death development.

We examined ERF102 as an AP2/ERF family transcription factor by using the method shown in Figure 3. MACD1 was a transcriptional activator, showed GCC-box-mediated GUS activity and nuclear localization (Supplementary Fig. S5).

To examine the function of ERF102 in PCD, we produced ERF102 OE plants. The expression of ERF102 increased in ERF102 OE plants (Supplementary Fig. 6B). ERF102 OE lines showed no apparent phenotypic variation compared with Columbia (Col-0) Arabidopsis wild-type plants. Necrosis by FB1 was more severe in ERF102 OE plants than in Col-0 control plants. Taken together, ERF102 positively regulates genes participating in cell death induction.

We showed that FCD is more severe in ERF102 OE plants than in Col-0 control plants. Mutual antagonism between jasmonic acid (JA)/ET and salicylic acid (SA) signaling is well known (Glazebrook 2005; Verhage et al. 2010). UV-C-inducible SA-responsive pathogenesis-related-1 (PR-1) is compromised in ERF102 (ERF5) or ERF103 (ERF6) OE plants (Moffat et al. 2012). It is possible that suppression of SA signaling by ERF102 OE is important for the FCD induction. To investigate this possibility, we co-treated ERF102 OE plants with FB1 and SA. We confirmed that $P R-1$ is induced by the spray treatment of $1 \mathrm{mM}$ SA (Supplementary Fig. S7A). Col0, ERF102 OE-1, and ERF102 OE-5 plants were treated with FB1 $3 \mathrm{~h}$ after SA treatment. FCD was normally induced and ERF102 OE-5 showed severe FCD in the presence of SA. Asai and associates (2000) showed that SA signaling is required for FCD in Arabidopsis protoplasts. These data suggest that the FCD phenotype does not depend on the suppression of SA signaling by ERF102 OE.

\section{ERF102 participates in ACD.}

AAL disrupts sphingolipid metabolism and subsequent PCD in its sensitive plants (Gilchrist 1997; Spassieva et al. 2002; Wang et al. 1996). Although the exact mechanisms of cell death activation and execution remain elusive, the presence of Asc, which is a homolog of the yeast longevity assurance gene (LAGl), prevents perturbations in sphingolipid metabolism and cell death (Brandwagt et al. 2000). Gechev and associates (2004) established that a knockout of Asc homolog lag one homologue 2 (loh2) in A. thaliana ecotype Wassilewskija plants was markedly more sensitive to AAL.

To further examine the participation of ERF102 in phytotoxin-induced cell death, we obtained loh2 (At3g19260) mutants in Col-0 from the SALK T-DNA collection (Egusa et al. 2013). Each mutant had T-DNA inserted into an exon or an intron of $\mathrm{LOH} 2$ and was named loh2-1 (SALK_018608C) (Egusa et al. 2013; Ternes et al. 2011) and loh2-2 (SALK 024192C), respectively (Supplementary Fig. S8A). AAL (1 $\mu$ M) induced cell death in loh 2 mutants. The loh 2 mutants showed high sensitivity to AAL, and were treated with low-concentration AAL $(0.02 \mu \mathrm{M})$ in the following experiments. To evaluate the participation of ERF102 in ACD, we generated the loh2-1/ erf102 double mutant (Fig. 7A and B), which showed reduced ACD (Fig. 7C and D). In addition, ERF102 expression was 

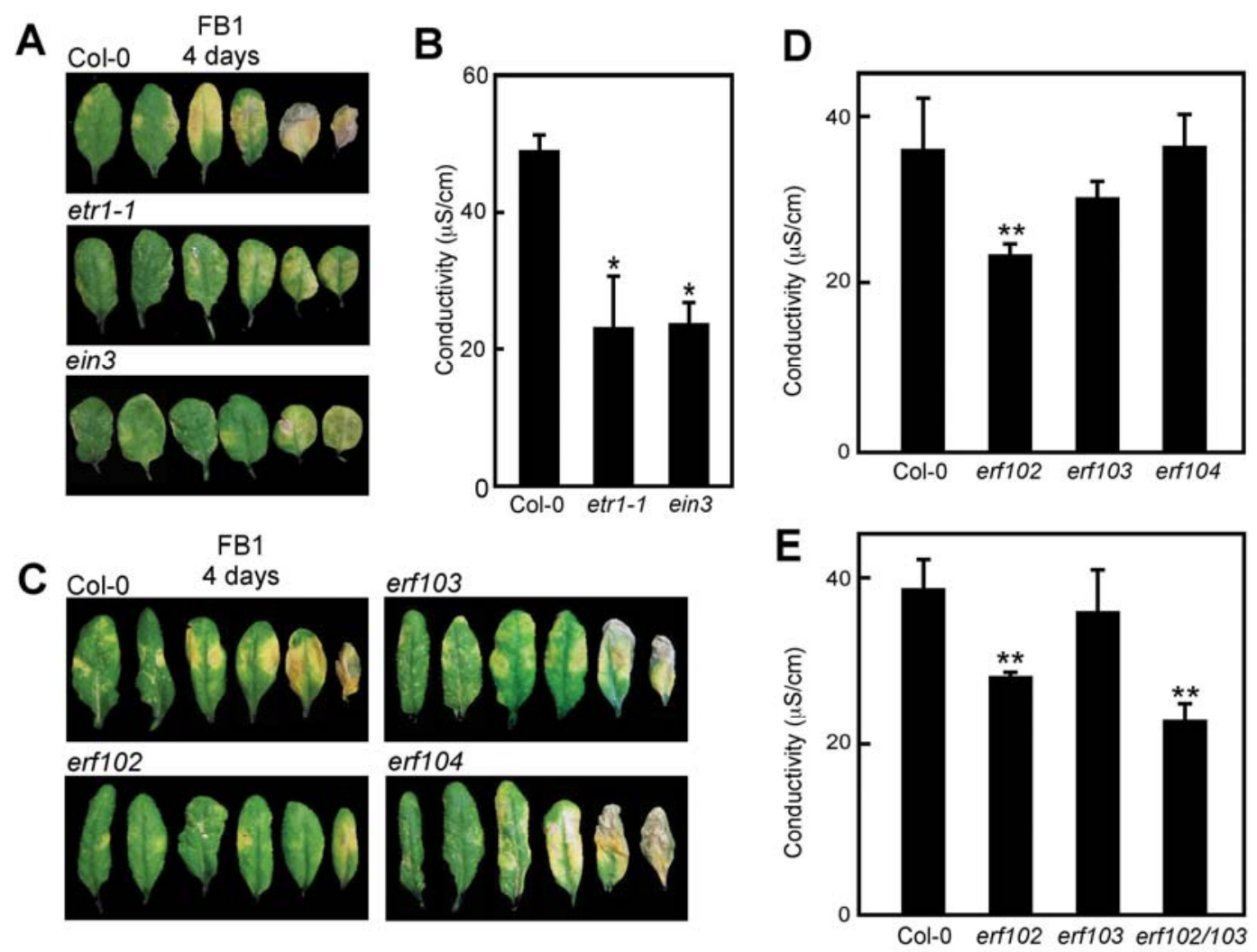

Fig. 5. Ethylene signaling mutants and erf102, erf102/103 double mutants compromise fumonisin B1 (FB1)-triggered cell death (FCD). A and B, Effects of knockouts ETR1-1 and EIN3. FCD shown in A was quantified by ion leakage from FB1-treated leaves in B. C and D, Effects of knockouts ERF102, $E R F 103$, and ERF104. FCD shown in C was quantified by ion leakage from FB1-treated leaves in D. E, Effects of knockouts ERF102, ERF103, and $E R F 102 / 103$ on FCD. Data are means \pm standard deviations from at least three independent experiments. Data underwent a Student's $t$ test: $* *$ and $*$ indicate $P<0.01$ and 0.05 , respectively, versus Col-0 control plants.

A ERF1
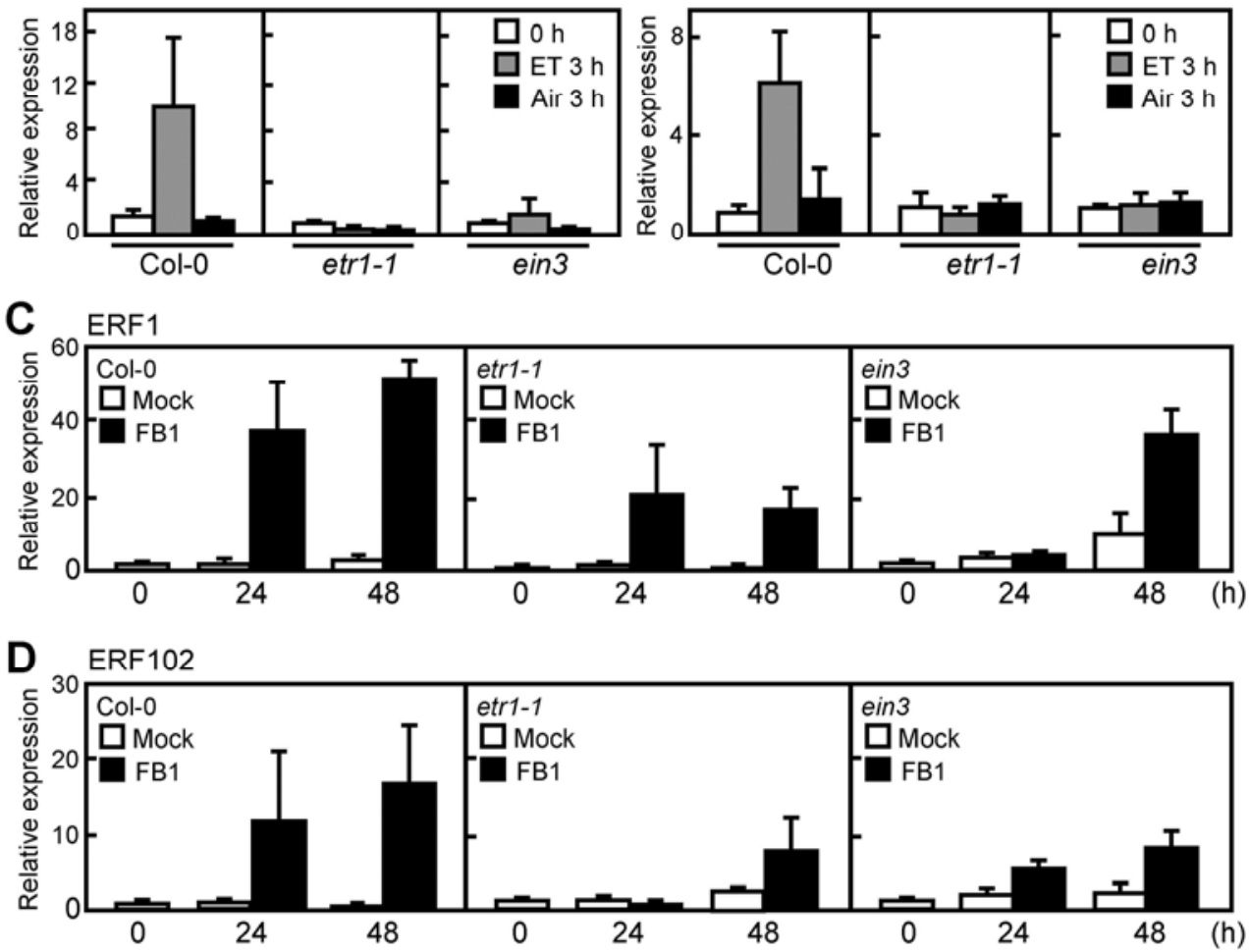

Fig. 6. Transcript accumulation of ERF102 in response to ethylene (ET) and fumonisin B1 (FB1). Expression levels of A, ERF1 and B, ERF102 after ET treatment in Col-0 (left), etr1-1 (middle), and ein3 (right). Actin was used as an internal standard. Data are means \pm standard deviations (SD) from three experiments. Expression profiles of $\boldsymbol{C}$, ERF1 and D, ERF102 after FB1 treatment in Col-0 (left), etr1-1 (middle), and ein3 (right). Actin was used as an internal standard. Data are means $\pm \mathrm{SD}$ from three experiments. 
induced by AAL treatment (Fig. 7E). Taken together, ERF102 participates in A. thaliana ACD.

Microarray analysis for ERF102 downstream targets.

To gain insight into genes regulated by ERF102, we profiled gene expression in ERF102 OE plants by using microarray analysis. ERF102 OE plants showed 274 upregulated and 374 downregulated genes (at least threefold changes; false discovery rate, $P<0.05$ ) (Supplementary Tables S1 and S2). Functional grouping based on the Arabidopsis Information Resource database annotation showed that various genes are upregulated or downregulated in ERF102 OE plants (Supplementary Fig. S9). To explore genes participating in PCD under control of ERF102, our microarray data were compared with microarray data for loh2 mutants treated with AAL (Gechev et al. 2004). ERF102 is a transcriptional activator and is induced by AAL. We focused on upregulated genes in both ERF102 OE plants and AAL-treated loh2 mutants (Fig. 8A). Thirty-four genes were selected as candidates for ERF102-regulated genes participating in PCD (Table 1). We examined the expression levels
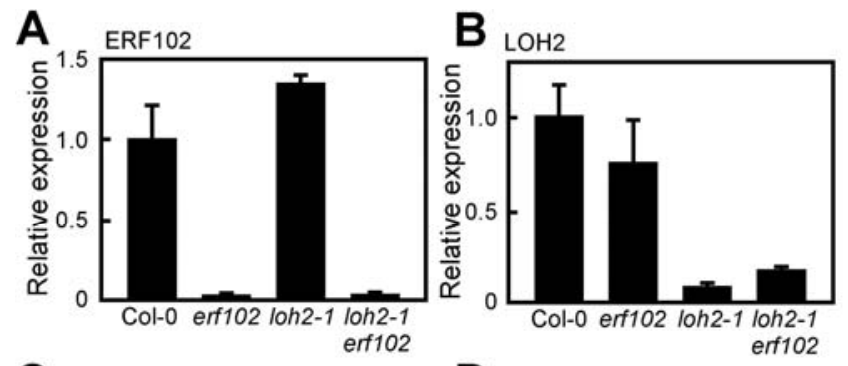

C
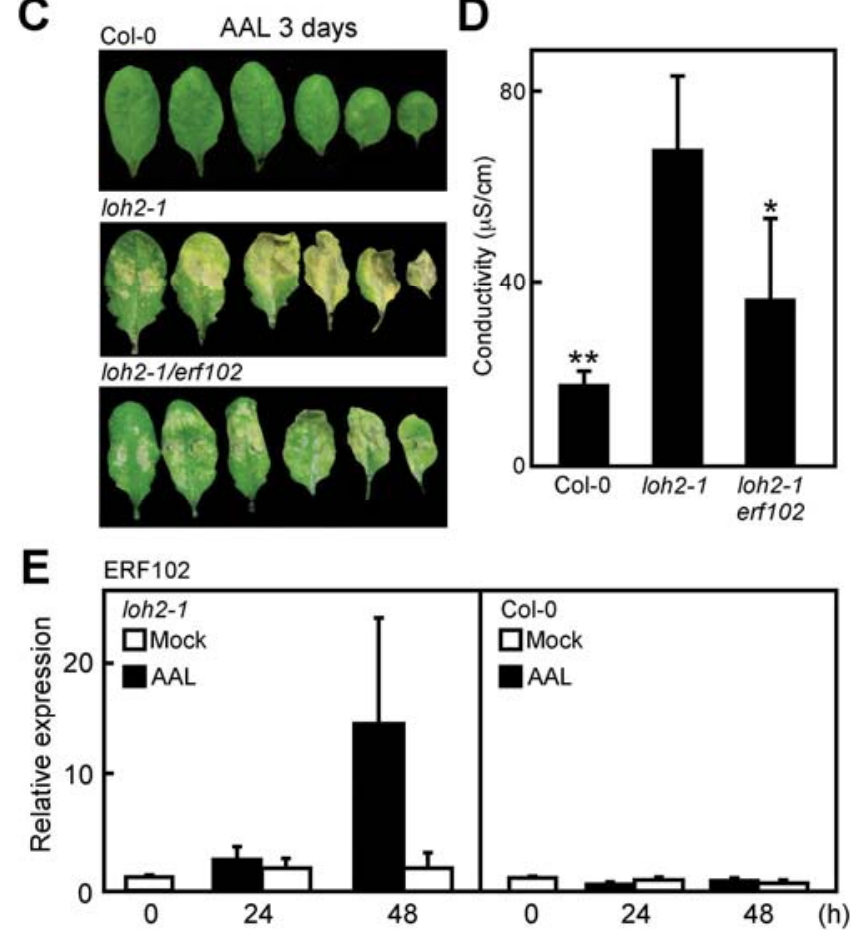

Fig. 7. loh2-1/erf102 double mutant compromises ACD. Expression levels of $\mathbf{A}$, ERF 102 and $\mathbf{B}$, LOH2 in Col-0 plants, erf102 and loh2-1 mutants, and loh2-1/erf102 double mutant. Actin was used as an internal standard. Data are means \pm standard deviations (SD) from three experiments. $\mathbf{C}$, Effects of knockout ERF102 on ACD in loh2-1 mutant. D, ACD quantified by ion leakage from AAL-treated leaves. Data are means \pm SD from at least three independent experiments. Data underwent a Student's $t$ test: ** and * indicate $P<0.01$ and 0.05 , respectively, versus loh2-1 mutant. $\mathbf{E}$, Expression profiles of ERF102 in response to AAL in loh2-1 mutant (left) and Col-0 plants (right). Actin was used as an internal standard. Data are means $\pm \mathrm{SD}$ from three experiments. of these 34 genes in loh2-1 and loh2-1/erf102 double mutants at 24 and $48 \mathrm{~h}$ after AAL-treatment by using quantitative reverse-transcriptase (qRT)-PCR analysis. Genes GLUTATHIONE S-TRANSFERASE TAU 2 (AtGSTU2) (At2g29480), GLUTATHIONE S-TRANSFERASE TAU 1 (AtGSTU1) (At2g29490), glycosyl hydrolase 17 (GH17) (At4g16260), and GH3.5, WES1 (At4g27260) stood out as possibly regulated by ERF102, because they were downregulated in the loh2-1/erf102 double mutant (Fig. 8B).

\section{DISCUSSION}

In this study, we identified MACD1 as the modulator of ACD in N. umbratica. MACD1 was a transcriptional activator, induced GCC-box-mediated GUS activity, and localized in the nucleus (Fig. 3), indicating that MACD1 has the features of an AP2/ERF transcription factor. MACD1 OE did not induce cell death in N. umbratica (Fig. 4A-C), indicating that MACD1 $\mathrm{OE}$ is not sufficient to induce cell death. Previously, we reported that ET signaling has important roles in ACD but ET treatment
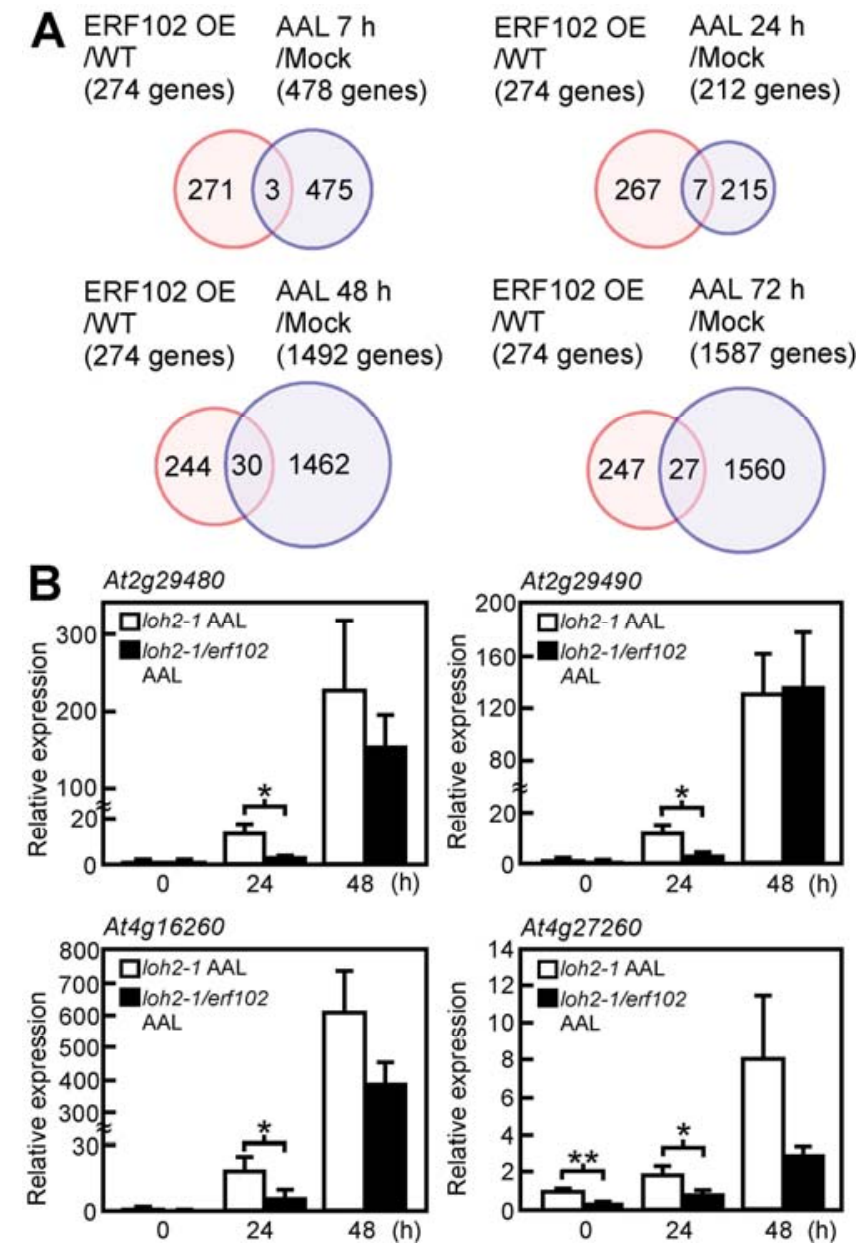

Fig. 8. Upregulated genes in ERF102 overexpression (OE) plants and AAL-treated plants. A, Comparison of upregulated genes in ERF102 OE plants to upregulated genes in response to AAL (obtained in microarray experiments by Gechev and associates [2004]). The Venn diagram indicates the number of genes with $>3$-fold (upregulated) expression in ERF102 OE plants or AAL-treated plants compared with wild-type or mock-treated plants, respectively. B, Transcript accumulation of At $2 g 29480$, At2g29490, At4g16260, and At4g27260 in response to AAL in loh2-1 and loh2-1/erf102 double mutants. Actin was used as an internal standard. Data are means \pm standard deviations from three experiments. Data underwent a Student's $t$ test: $* *$ and $*$ indicate $P<0.01$ and 0.05 , respectively, versus the loh2-1 mutant. 
itself does not induce cell death and increase ion leakage (Mase et al. 2012). Taken together, the ET signaling pathway seems to be required for full induction of PCD. In this study, the necrotic symptom of ACD was more severe in MACD1 OE plants (Fig. 4D and E). MACD1 was a transcriptional activator (Fig. 3A and B). These results suggest that MACD1 positively regulates factors participating in cell death progression. As an example of cell death induced by ERF OE, NbCD1 OE induces HR-like cell death in N. benthamiana (Nasir et al. 2005). NtERF3 and ERF that contain the EAR motif from both tobacco ( $N$. benthamiana) and rice also induce HR-like cell death when overproduced in tobacco plants (Ogata et al. 2012). NbCD1 and NtERF3 showed transcriptional repressor activity through their EAR motif, which was necessary for NbCD1 and NtERF3 to cause HR-like cell death, suggesting that NbCD1 and NtERF3 negatively regulate the negative regulator of cell death.

Multiple alignment analyses showed that MACD1 homologs in $A$. thaliana are classified into A. thaliana ERF group IX (Nakano et al. 2006). To evaluate the participation of MACD1 homologs in toxin-induced PCD in A. thaliana, erf102, erf103, and erf104 mutants were treated with FB1 (Fig. 5C and D). The erf102 mutant showed significantly reduced FCD; there-

Table 1. Genes upregulated in ERF102 overexpression (OE) plants and AAL-treated plants ${ }^{\mathrm{a}}$

\begin{tabular}{|c|c|c|c|c|c|c|c|c|c|c|c|}
\hline \multirow[b]{2}{*}{ AGI } & \multirow[b]{2}{*}{ Description } & \multicolumn{2}{|c|}{ ERF OE } & \multicolumn{2}{|c|}{ AAL 7} & \multicolumn{2}{|c|}{ AAL 24} & \multicolumn{2}{|c|}{ AAL 48} & \multicolumn{2}{|c|}{ AAL 72} \\
\hline & & FC & $P$ value & FC & $P$ value & FC & $P$ value & FC & $P$ value & FC & $P$ value \\
\hline \multicolumn{12}{|l|}{ Defense } \\
\hline AT5G44430 & PDF1.2c (plant defensin 1.2c) & 140 & 4.95E-09 & $\ldots$ & $\ldots$ & $\ldots$ & $\ldots$ & 4.3 & $1.82 \mathrm{E}-06$ & 11.1 & $2 \mathrm{E}-09$ \\
\hline AT5G44420 & PDF1.2 (plant defensin 1.2) & 50.4 & $1.79 \mathrm{E}-08$ & $\cdots$ & $\ldots$ & $\ldots$ & $\ldots$ & 8.47 & 7.96E-09 & 23.8 & $1.87 \mathrm{E}-10$ \\
\hline AT5G22570 & WRKY38 & 5.79 & 0.001805 & $\ldots$ & $\ldots$ & 4.32 & $1.9 \mathrm{E}-06$ & 8.76 & $6.67 \mathrm{E}-09$ & 4.76 & $6.75 \mathrm{E}-07$ \\
\hline AT2G26020 & PDF1.2b (plant defensin $1.2 b)$ & 144 & $2.59 \mathrm{E}-10$ & $\ldots$ & $\ldots$ & $\ldots$ & $\ldots$ & 4.98 & 4.4E-07 & 13.5 & $9.04 \mathrm{E}-10$ \\
\hline AT2G26010 & PDF1.3 (plant defensin 1.3) & 97.1 & $6.05 \mathrm{E}-14$ & $\ldots$ & $\ldots$ & $\ldots$ & $\ldots$ & 3.87 & $5.55 \mathrm{E}-06$ & 7.82 & $1.29 \mathrm{E}-08$ \\
\hline AT1G06160 & $\begin{array}{l}\text { AP2/ERF } 59 \text { DNA binding/transcription activator/ } \\
\text { transcription factor (ORA59) }\end{array}$ & 5.21 & $1.02 \mathrm{E}-05$ & $\ldots$ & $\ldots$ & $\ldots$ & $\ldots$ & 4.1 & $3.35 \mathrm{E}-06$ & 3.84 & $6.98 \mathrm{E}-06$ \\
\hline AT3G49110 & PRXCA (PEROXIDASE CA) & 10.7 & 0.000685 & $\ldots$ & $\ldots$ & $\ldots$ & $\ldots$ & 4.28 & $3.01 \mathrm{E}-06$ & 12 & $2.24 \mathrm{E}-09$ \\
\hline \multicolumn{12}{|l|}{ Development } \\
\hline AT4G27260 & GH3.5, WES1 & 9.12 & 0.002481 & $\ldots$ & $\ldots$ & $\ldots$ & $\ldots$ & 2.42 & 1.E-03 & $\ldots$ & $\ldots$ \\
\hline AT3G44750 & HDA3 (HISTONE DEACETYLASE 3) & 3.13 & $2.94 \mathrm{E}-07$ & $\ldots$ & $\ldots$ & $\ldots$ & $\ldots$ & 3.86 & $5.88 \mathrm{E}-06$ & $\ldots$ & $\ldots$ \\
\hline AT3G16360 & AHP4 (HPT PHOSPHOTRANSMITTER 4) & 3.61 & 0.000622 & 3.25 & 0.003678 & $\ldots$ & $\ldots$ & $\ldots$ & $\ldots$ & $\ldots$ & $\ldots$ \\
\hline AT2G44790 & UCC2 (UCLACYANIN 2) & 5.72 & 0.0003 & $\ldots$ & $\ldots$ & $\ldots$ & $\ldots$ & 14.9 & $1.06 \mathrm{E}-09$ & 7.72 & $1.78 \mathrm{E}-08$ \\
\hline \multicolumn{12}{|l|}{ Metabolism } \\
\hline AT5G61160 & AACT1 (anthocyanin 5-aromatic acyltransferase 1) & 6.42 & $1.53 \mathrm{E}-06$ & $\cdots$ & $\cdots$ & $\cdots$ & $\cdots$ & $\ldots$ & $\ldots$ & 3.05 & 8.97E-05 \\
\hline AT3G43190 & SUS4 (sucrose synthase 4) & 4.24 & 0.000655 & $\ldots$ & $\ldots$ & $\ldots$ & $\ldots$ & 4.36 & 1.79E-06 & 6.95 & 3.03E-08 \\
\hline AT1G56650 & PAP1 (PRODUCTION OF ANTHOCYANIN & & & & & & & & & & \\
\hline & PIGMENT 1) & 3.7 & 0.000219 & $\cdots$ & $\ldots$ & $\cdots$ & $\cdots$ & 12.4 & $1.39 \mathrm{E}-09$ & ... & $\ldots$ \\
\hline \multicolumn{12}{|l|}{ Senescence } \\
\hline AT5G01600 & ATFER1 (ferric iron binding/iron ion binding) & 3.07 & 2.23E-09 & .. & $\ldots$ & $\cdots$ & $\ldots$ & 5.68 & $1.36 \mathrm{E}-07$ & 6.08 & 7.84E-08 \\
\hline \multicolumn{12}{|c|}{ 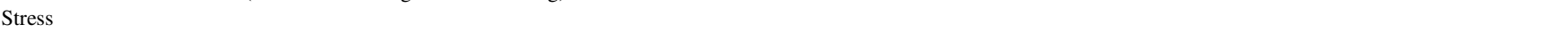 } \\
\hline AT4G08770 & Peroxidase, putative & 3.83 & 0.004602 & $\ldots$ & $\ldots$ & $\ldots$ & $\ldots$ & 6.47 & $4.8 \mathrm{E}-08$ & 33.1 & $1.07 \mathrm{E}-10$ \\
\hline AT3G09270 & $\begin{array}{l}\text { ATGSTU8 (GLUTATHIONE S-TRANSFERASE } \\
\text { TAU 8) }\end{array}$ & 3.77 & 0.002656 & $\ldots$ & $\ldots$ & 4.57 & $1.11 \mathrm{E}-06$ & $\ldots$ & $\ldots$ & $\ldots$ & $\ldots$ \\
\hline AT2G29490 & $\begin{array}{l}\text { ATGSTU1 (GLUTATHIONE S-TRANSFERASE } \\
\text { TAU 1) }\end{array}$ & 3.96 & $1.55 \mathrm{E}-08$ & $\ldots$ & $\ldots$ & $\ldots$ & $\ldots$ & 11.8 & $1.56 \mathrm{E}-09$ & 11.8 & $1.55 \mathrm{E}-09$ \\
\hline AT4G16260 & Glycosyl hydrolase 17 & 3.96 & 0.002085 & $\ldots$ & $\ldots$ & $\ldots$ & $\ldots$ & 18.8 & $3.24 \mathrm{E}-10$ & 31.5 & $1.15 \mathrm{E}-10$ \\
\hline Transporter & & & & & & & & & & & \\
\hline AT1G58340 & ZF14 (antiporter/ drug transporter/ transporter) & 6.55 & 0.005817 & $\ldots$ & $\ldots$ & $\cdots$ & $\ldots$ & 11.5 & $2 \mathrm{E}-09$ & 35.8 & $1.2 \mathrm{E}-10$ \\
\hline Unknown & & & & & & & & & & & \\
\hline AT5G44480 & DUR (DEFECTIVE UGE IN ROOT) & 3.44 & 0.001349 & $\ldots$ & $\ldots$ & 3.71 & $1.42 \mathrm{E}-05$ & 19.6 & $2.94 \mathrm{E}-10$ & 39.1 & $8.76 \mathrm{E}-11$ \\
\hline AT5G22791 & Unknown protein & 5.46 & $3.17 \mathrm{E}-06$ & .. & $\ldots$ & $\ldots$ & $\ldots$ & 6.53 & 4.97E-08 & $\cdots$ & $\ldots$ \\
\hline AT5G05600 & $\begin{array}{l}\text { Oxidoreductase, } 2 \mathrm{OG}-\mathrm{Fe}(\mathrm{II}) \text { oxygenase family } \\
\text { protein }\end{array}$ & 4.07 & $3.35 \mathrm{E}-05$ & 4.4 & $1.45 \mathrm{E}-06$ & $\cdots$ & $\ldots$ & $\cdots$ & $\cdots$ & $\ldots$ & $\ldots$ \\
\hline AT4G15970 & Unknown protein & 6.13 & 0.000721 & $\ldots$ & $\ldots$ & $\ldots$ & $\ldots$ & $\ldots$ & $\ldots$ & 3.31 & $3.23 \mathrm{E}-05$ \\
\hline AT3G55970 & $\begin{array}{l}\text { Oxidoreductase, } 2 \mathrm{OG}-\mathrm{Fe}(\mathrm{II}) \text { oxygenase family } \\
\text { protein }\end{array}$ & 10.7 & 0.001212 & $\ldots$ & $\ldots$ & $\ldots$ & $\ldots$ & 36.7 & $9.26 \mathrm{E}-11$ & 65.1 & $5.31 \mathrm{E}-11$ \\
\hline AT3G49620 & $\begin{array}{l}\text { DIN11 (DARK INDUCIBLE 11); iron ion } \\
\text { binding/oxidoreductase (DIN11) }\end{array}$ & 6.85 & $1.3 \mathrm{E}-09$ & $\ldots$ & $\ldots$ & 3.88 & 0.000441 & 65.4 & $5.96 \mathrm{E}-11$ & 8.44 & $1.38 \mathrm{E}-08$ \\
\hline AT3G23550 & MATE efflux family protein & 3.44 & 3.87E-06 & $\ldots$ & $\ldots$ & $\ldots$ & $\ldots$ & $\ldots$ & $\ldots$ & $\ldots$ & $\ldots$ \\
\hline AT2G43870 & Polygalacturonase, putative/pectinase, putative & 3.53 & $3.66 \mathrm{E}-05$ & $\ldots$ & $\ldots$ & $\ldots$ & $\ldots$ & 4.22 & 0.000188 & $\ldots$ & $\ldots$ \\
\hline AT2G43590 & Chitinase, putative & 3.2 & 8.78E-09 & $\ldots$ & $\ldots$ & $\ldots$ & $\ldots$ & $\ldots$ & $\ldots$ & 5.24 & 3.69E-07 \\
\hline AT2G43580 & Chitinase, putative & 3.46 & $8.61 \mathrm{E}-06$ & $\ldots$ & $\ldots$ & $\ldots$ & $\ldots$ & 4.82 & $6.02 \mathrm{E}-07$ & 10.7 & 2.43E-09 \\
\hline AT2G39030 & $\begin{array}{l}\text { GCN5-related N-acetyltransferase (GNAT) family } \\
\text { protein }\end{array}$ & 41.3 & $3.64 \mathrm{E}-06$ & $\ldots$ & $\ldots$ & $\ldots$ & $\ldots$ & 18.3 & $3.48 \mathrm{E}-10$ & 14.9 & $6.42 \mathrm{E}-10$ \\
\hline AT2G37870 & $\begin{array}{l}\text { Protease inhibitor/seed storage/lipid transfer protein } \\
\text { (LTP) family protein } \\
\text { ATGSTU2 (GLUTATHIONE S-TRANSFERASE }\end{array}$ & 3.25 & $1.24 \mathrm{E}-05$ & $\cdots$ & $\ldots$ & $\cdots$ & $\ldots$ & 3.36 & 4.13E-05 & $\cdots$ & $\cdots$ \\
\hline & TAU 2) & 7.43 & 0.001261 & $\ldots$ & $\ldots$ & 3.01 & 9.97E-05 & 51.4 & $6.43 \mathrm{E}-11$ & 87.9 & 4.41E-11 \\
\hline AT1G73325 & $\begin{array}{l}\text { trypsin and protease inhibitor family protein/Kunitz } \\
\text { family protein }\end{array}$ & 7.41 & $1.22 \mathrm{E}-08$ & 3.66 & 0.004237 & $\ldots$ & $\ldots$ & $\ldots$ & $\ldots$ & $\ldots$ & $\ldots$ \\
\hline AT1G26450 & $\beta-1,3$-Glucanase-related & 3.24 & 4.64E-05 & $\ldots$ & $\ldots$ & $\ldots$ & $\ldots$ & $\ldots$ & $\ldots$ & 3.34 & $6.74 \mathrm{E}-05$ \\
\hline AT1G15870 & $\begin{array}{l}\text { Mitochondrial glycoprotein family protein/MAM33 } \\
\text { family protein }\end{array}$ & 4 & 0.001935 & $\ldots$ & $\ldots$ & $\ldots$ & $\ldots$ & 4.23 & 2.81E-06 & 3.28 & $5.81 \mathrm{E}-05$ \\
\hline AT1G09470 & Unknown protein & 3.47 & 0.005066 & $\ldots$ & $\ldots$ & $\ldots$ & $\ldots$ & 4.81 & $1.1 \mathrm{E}-06$ & $\ldots$ & $\ldots$ \\
\hline AT3G49840 & Unknown protein & 7.13 & $5.6 \mathrm{E}-08$ & $\ldots$ & $\ldots$ & $\ldots$ & $\ldots$ & 7.34 & $1.96 \mathrm{E}-08$ & $\ldots$ & $\ldots$ \\
\hline
\end{tabular}

${ }^{\mathrm{a}} \mathrm{ERF}=$ ethylene response factor, $\mathrm{FC}=$ fold change 
fore, we think ERF102 is a MACD1 ortholog in A. thaliana. However, the AP2/ERF superfamily in A. thaliana contains 122 members (Nakano et al. 2006). Possibly, some ERF are regulated by the same stimuli and bind to the same promoter element; therefore, a high level of functional redundancy may be expected. This notion is supported by Moffat and associates (2012), who found that ERF5 (ERF102) and ERF6 (ERF103) have redundant roles in JA/ET-mediated defense against Botrytis cinerea in A. thaliana; although no marked difference in susceptibility to $B$. cinerea was observed in either the erf5 or erf6 mutant, the erf5/erf6 double mutant showed a marked increase in susceptibility. For this functional redundancy, the roles of ERF102 and ERF103 in FCD were investigated using the erf102/erf103 double mutant (Moffat et al. 2012). The erf102/erf103 double mutant showed lower conductivity than the erf102 single mutant (Fig. 5E), suggesting that ERF103 also contributes FCD induction.

ERF102 OE plants showed activation of some defenserelated genes, such as PDF1.2 genes and chitinase. Our microarray data agreed with Moffat and associates (2012), who showed that JA-mediated defense-responsible genes, such as PDF1.2 genes, are upregulated in ERF5 (ERF102) OE plants and ERF6 (ERF103) OE plants. They also showed that ERF5 and ERF6 act as positive regulators of JA-mediated defense against $B$. cinerea and as negative regulators of UV-C-induced $P R-1$ expression, which is an SA-inducible gene. The mutual antagonism between the JA/ET and SA signaling pathways is well-established (Glazebrook 2005; Verhage et al. 2010). However, Son and associates (2012) showed that ERF5 (ERF102) appears to negatively regulate plant defense against the necrotroph fungal pathogen Alternaria brassicicola and positively regulate SA signaling and plant defense against bacterial pathogen Pseudomonas syringae pv. tomato DC3000. Although the results of these studies conflict, they suggest that ERF102 participates not only in the induction of PCD but also in response to biotic stress. Now, many examples exist of Arabidopsis thaliana IX ERF OE modulating plant defense. ERF1 (At3g23240) was suggested to act as an integrator of JA- and ET-dependent pathways in A. thaliana (Lorenzo et al. 2003). ERF1 OE activates the expression of several defense-related genes, including PDF1.2 and basic chitinase (ChiB) (Lorenzo et al. 2003; Solano et al. 1998), and confers resistance to several fungi, including B. cinerea (Berrocal-Lobo et al. 2002). ORA59 OE (At1g06160) activates the transcription of PDF1.2 and increases resistance against the fungus $B$. cinerea (Pré et al. 2008). AtERF2 OE (At5g47220) (Brown et al. 2003; McGrath et al. 2005) or AtERF14 OE (At1g04370) (Oñate-Sánchez et al. 2007) also causes high levels of PDF1.2 and ChiB gene expression in transgenic $A$. thaliana. AtERF2 OE plants show resistance to Fusarium oxysporum (McGrath et al. 2005). Overexpression of several ERF modifies defense gene expression and resistance to various pathogens but little has been reported on the participation of ERF in PCD induction. Therefore, we think our results provide new insights into the function of ERF in plant PCD.

Microarray analysis showed that ERF102 OE affects the expressions of various genes but showed no clear trend of specific pathways being affected. To further investigate genes regulated by ERF102 in ACD, our microarray data were compared with microarray data for loh 2 mutants treated with AAL (Gechev et al. 2004) (Fig. 8A). We selected 34 upregulated genes in both ERF102 OE plants and AAL-treated plants (Table 1) and investigated the expression profiles of 34 genes by using the microarray databases. As a result, we found that most of the 34 genes are upregulated by JA or ET/JA treatment (Supplementary Fig. S10A), suggesting that ERF102 OE mimics the JA signaling pathway. Exogenous JA treatment has a pro- motional effect on the susceptibility to Alternaria alternata $\mathrm{f}$. sp. lycopersici in tomato (Egusa et al. 2009). We also treated $N$. umbratica leaves with JA and inoculated A. alternata f. sp. lycopersici. The disease symptoms and fungal biomass were developed compared with control plants. Our data suggest that AAL does not only induce PCD in host plants but also promotes susceptibility to A. alternata f. sp. lycopersici by manipulating host plant JA signaling via ERF102.

Four genes were identified as putative targets of ERF102 by using qRT-PCR analysis (Fig. 8B). ERF102 induced GCC-boxmediated GUS activity. We examined whether a GCC-box is found in 2-kb upstream regions of four genes. We found a GCCbox (AGCCGCC) in only the upstream region of At4g16260; possibly, At4g16260 is directly regulated by ERF102 and has a role in plant PCD. At4g16260 GH17, which is a member of the PR-2 protein groups, encodes $\beta$-1,3-endoglucanase (Doxey et al. 2007; Mahalingam et al. 2003). GH17 is highly induced by pathogen stress, such as by A. brassicicola, B. cinerea, Erysiphe orontii, and Phytophthora infestans (Doxey et al. 2007). Proteomics analysis shows that the protein level of GH17 increases in response to A. brassicicola (Mukherjee et al. 2010). Arabidopsis thaliana GH17 T-DNA mutants show increased susceptibility to cyst nematode Heterodera schachtii and GH17 OE plants show reduced nematode susceptibility, suggesting a potential role of host GH17 in the defense response against H. schachtii infection (Hamamouch et al. 2012). These observations indicate that $\mathrm{GH} 17$ mainly has a role in plant defense response. Little knowledge exists of $\mathrm{GH} 17$ affecting plant PCD. Pepper (Capsicum annuum) PR-10 protein was identified as a leucine-rich repeat protein1 (LRR1)-interacting partner (Choi du et al. 2012). Not only does PR-10 confer resistance to pathogens but transient expression of PR-10 also triggers HR cell death in pepper and $N$. benthamiana leaves, which are amplified by LRR1 coexpression as a positive regulator. Possibly, some PR proteins induced by pathogen attack also contribute to PCD induction.

The results of this study show a role for MACD1 and ERF102 in phytotoxin-induced cell death: they regulate genes participating in cell death development. We identified the genes under control of ERF102 during ACD in A. thaliana. Future studies will focus on the key target genes of ERF102 responsible for plant PCD.

\section{MATERIALS AND METHODS}

\section{Plant growth conditions.}

$N$. umbratica and $N$. benthamiana plants were grown in environmentally controlled growth cabinets under a 16-h photoperiod and an 8 -h dark period at $23^{\circ} \mathrm{C}$. A. thaliana plants were grown in environmentally controlled growth cabinets under a 10 -h photoperiod and a 14 -h dark period at $23^{\circ} \mathrm{C}$.

\section{Mutants and T-DNA insertion lines.}

The erf102 (SALK_076967), erf103 (SALK_087356), loh2-1 (SALK_018608C), and loh2-2 (SALK_024192C) mutants of A. thaliana (ecotype, Columbia-0) were obtained from the Arabidopsis Biological Resource Center (ABRC); ein3 (Roman et al. 1995) and etrl-1 mutants (Chang et al. 1993) were obtained from the ABRC; the erf104 mutant (Bethke et al. 2009) was provided by J. Lee (University of Cologne); and the erf102/ erf103 double mutant (Moffat et al. 2012) was provided by M. R. Knight (Durham University).

\section{VIGS.}

We amplified cDNA fragments of each gene from the $N$. umbratica cDNA library as templates using primers listed in Supplementary Table S3, and the DNA fragments were ligated 
into pTV00 vector as described by Ratcliff and associates (2001). The constructs containing these inserts were designated pTRV00:NuERF1 (TRV:NuERF1), pTRV00:NuERF2 (TRV: NuERF2), pTV00:NuERF4 (TRV:NuERF4), and pTV00: NuERF5 (TRV:NuERF5). pTV00:EIL (TRV:EIL) and pTV00: EIL5 (TRV:EIL5) were described by Mase and associates (2012). pTV00 that contained no inserts was used as a control. For VIGS assay as described by Asai and associates (2010), pBINTRA6 or pTV00 and its derivatives were introduced into Agrobacterium strain GV3101 by electroporation (Bio-Rad, Hercules, CA, U.S.A.). After an additional 3 to 4 weeks, plants were analyzed by treatment with AAL.

\section{Agrobacterium tumefaciens-mediated transient expression (agroinfiltration) in N. umbratica.}

The following primers were used to amplify cDNA fragments of MACD1 from the $N$. umbratica cDNA library. Restriction sites were added to the $5^{\prime}$ ends of the forward and reverse primers for cloning into the pGreen binary vector (Hellens et al. 2000): MACD1-F-ClaI (5'-CCATCGATATGGC ATCACCACAAGAGAATTGCAC-3') and MACD1-R-BamHI (5'-CGGATCCTCATATCATGACAAGCTGAGAATAGGC-3'). The binary plasmids were transformed into Agrobacterium sp. strain GV3101. Agroinfiltration was done as described by Asai and associates (2008).

\section{RT-PCR.}

Total RNA from N. umbratica and Arabidopsis thaliana leaves was prepared using TRIZOL reagent (Invitrogen, Carlsbad, CA, U.S.A.) according to the manufacturer's procedure. Reverse transcription was done by using ReverTra Ace -a-, and qRT-PCR analysis was done by using the STEPONEPLUS REAL-TIME PCR system (Applied Biosystems, Foster City, CA, U.S.A.) with POWER SYBR GREEN PCR MASTER MIX (Applied Biosystems). EF-1 $\alpha$ and actin were used as a control in $N$. umbratica and A. thaliana, respectively. The gene-specific primers of each sequence are listed in Supplementary Table S4.

\section{Toxin treatment.}

AAL treatment: AAL $(1 \mu \mathrm{M})$ or AAL $(0.02 \mu \mathrm{M})$ was infiltrated into $N$. umbratica or A. thaliana leaves, respectively, by using a needleless 1 -ml syringe. FB1 treatment: FB1 $(5 \mu \mathrm{M})$ was infiltrated into $A$. thaliana leaves by using a needleless $1-\mathrm{ml}$ syringe.

\section{Measurements of cell death.}

Cell death was measured as electrolyte leakage from toxintreated leaves as described by Asai and associates (2010). For a conductivity test using $N$. umbratica, five discs per leaf $(5 \mathrm{~mm}$ in diameter) were obtained from the treated leaf. For Arabidopsis, six discs (5 $\mathrm{mm}$ in diameter) obtained from all phytotoxin-treated leaves were used. These leaf discs were immersed in $10 \mathrm{ml}$ of ultrapure water for $4 \mathrm{~h}$ at room temperature with gentle shaking. The conductivity of the solution was measured by using a pH/COND METER D-54 (HORIBA, Kyoto, Japan).

\section{Assays of transcriptional activity in $N$. benthamiana.}

For reporter plasmids, six tandem repeats of GAL4 upstream activation sequence 5'-CGGAGTACTGTCCTCCG-3' were fused upstream of the minimal $35 \mathrm{~S}$ promoter ( $246 \mathrm{bp}$ ) sequence and were cloned into pGreen binary vector (Hellens et al. 2000). Then, the cDNA of the GUS reporter gene containing one intron was cloned behind the synthetic promoter. For effector plasmids, C-terminal cDNA fragments of MACD1 (amino acid positions 205 to 273), ERF102 (amino acid posi- tions 81 to 170 ), or the VP16 activation domain (amino acid positions 413 to 490) were fused downstream of the GAL4 DNA binding domain (amino acid positions 1 to 147) and were cloned into pGreen under the control of the $35 \mathrm{~S}$ promoter. For reference plasmids, the cDNA fragment of luciferase (LUC) containing one intron was cloned into pGreen under the control of the $35 \mathrm{~S}$ promoter. Transient assays were done using the agroinfiltration method described by Ishihama and associates (2011).

\section{GFP fusion constructs for expression in $N$. benthamiana.}

For subcellular localization analysis, cDNA fragments of MACD1 and ERF102 were cloned into pGWB405 and pGWB406, respectively, which fused GFP to the C terminus and $\mathrm{N}$ terminus, respectively, of the protein (Nakagawa et al. 2007). Each plasmid was transformed into Agrobacterium strain GV3101. Infiltration of Agrobacterium was done at an optical density at $600 \mathrm{~nm}$ of 0.5 .

\section{Transient expression to evaluate GCC-box-mediated GUS activity in $N$. benthamiana.}

For a reporter gene construct, a 29-bp region containing the GCC box sequence from the $A$. thaliana HLS1 gene (5'-ATGA GTTAACGCAGACATAGCCGCCATTT-3') was multimerized four times. For reporter plasmids, four tandem repeats of the 29-bp region containing the mutated GCC box (mGCC) sequence (5'-ATGAGTTAACGCAGACATAACCACCATTT-3') were fused upstream of the minimal $35 \mathrm{~S}$ promoter $(-46)$ and were cloned into pGreen. The cDNA of the GUS reporter gene containing one intron was then cloned behind the synthetic promoter. For effector plasmids, full-length MACD1 or ERF102 was cloned into pGreen under the control of the $35 \mathrm{~S}$ promoter. For reference plasmids, the cDNA fragment of LUC containing one intron was cloned into pGreen under the control of the $35 \mathrm{~S}$ promoter. Transient assays were done using the agroinfiltration method described by Ishihama and associates (2011).

\section{Microscopy.}

Epidermal cell layers of $N$. benthamiana leaves were assayed for fluorescence $48 \mathrm{~h}$ after agroinfiltration. Cells were visualized using a fluorescence microscope (AXIO IMAGER M1; Carl Zeiss, Oberkochen, Germany) with fluorescent filters: filter set 38HE (excitation BP 470/40, beam splitter FT 395, emission BP 525/50) for GFP and filter set 49 (excitation G 365, beam splitter FT 395, emission BP 445/50) for DAPI. Images were collected by using a CCD camera (AXIO CAM HRc; Carl Zeiss).

\section{Microarray analysis.}

Three-week-old wild-type and ERF102 OE leaves were used for microarray analysis that included replicated experiments $1,2,3$, and 4. Total RNA was prepared from these leaves using TRIZOL reagent (Invitrogen) according to the manufacturer's procedure. The two-color microarray experiments were done using the Agilent $A$. thaliana OLIGO DNA MICROARRAY with a capacity of 44,000 (ver. 4; Agilent Technologies, Santa Clara, CA, U.S.A.) according to the manufacturer's 60mer oligo microarray processing protocol. Total RNA (200 ng) from each plant sample was used to prepare Cy3-labeled or Cy5-labeled cRNA, using a LOW INPUT QUICK AMP LABELING KIT (Agilent Technologies). Hybridized and washed arrays were scanned at maximum laser intensity in the $\mathrm{Cy} 3$ channel using an Agilent Technologies MICROARRAY SCANNER (Agilent Technologies). Normalization was done using Linear and LOWESS normalization. After normalization, genes scored as present in all genotypes underwent further analysis. Upregulated or downregulated genes with greater than threefold 
changes in expression ratio (wild-type plants versus ERF102 OE plants) were selected in the experiments.

\section{Data and statistical analysis.}

At least three repetitions with individual biological sample sets were used for statistical treatment of the data results. The data are expressed as mean values; error bars indicate the standard error. The data underwent a Student's $t$ test to evaluate their significances of difference.

\section{ACKNOWLEDGMENTS}

We thank D. C. Baulcombe for the pTV00 vector, P. Mullineaux and R. Hellens for the pGreen vector, T. Nakagawa for the pGWB vectors, J. Lee for the erf104 mutant, M. R. Knight for the erf102/erf103 mutant, the Leaf Tobacco Research Center, Japan Tobacco for $N$. umbratica seed, and M Egusa for technical assistance. This work was supported by a Grant-in-Aid for Scientific Research (B) (20380028, 23380025) from the Japan Society of the Promotion of Science and Grant-in-Aid for Japan Society for the Promotion of Science Fellows (10J05393).

\section{LITERATURE CITED}

Alonso, J. M., Stepanova, A. N., Solano, R., Wisman, E., Ferrari, S., Ausubel, F. M., and Ecker, J. R. 2003. Five components of the ethyleneresponse pathway identified in a screen for weak ethylene-insensitive mutants in Arabidopsis. Proc. Natl. Acad. Sci. U.S.A. 100:2992-2997.

An, F., Zhao, Q., Ji, Y., Li, W., Jiang, Z., Yu, X., Zhang, C., Han, Y., He, W., Liu, Y., Zhang, S., Ecker, J. R., and Guo, H. 2010. Ethyleneinduced stabilization of ETHYLENE INSENSITIVE3 and EIN3LIKE1 is mediated by proteasomal degradation of EIN3 binding F-box 1 and 2 that requires EIN2 in Arabidopsis. Plant Cell 22:2384-2401.

Arabidopsis Genome Initiative. 2000. Analysis of the genome sequence of the flowering plant Arabidopsis thaliana. Nature 408:796-815.

Asai, T., Stone, J. M., Heard, J. E., Kovtun, Y., Yorgey, P., Sheen, J., and Ausubel, F. M. 2000. Fumonisin B1-induced cell death in Arabidopsis protoplasts requires jasmonate-, ethylene-, and salicylate-dependent signaling pathways. Plant Cell 12:1823-1836.

Asai, S., Ohta, K., and Yoshioka, H. 2008. MAPK signaling regulates nitric oxide and NADPH oxidase-dependent oxidative bursts in Nicotiana benthamiana. Plant Cell 20:1390-1406.

Asai, S., Mase, K., and Yoshioka, H. 2010. A key enzyme for flavin synthesis is required for nitric oxide and reactive oxygen species production in disease resistance. Plant J. 62:911-924.

Bailey, B. A., Dean, J. F. D., and Anderson, J. D. 1990. An ethylene biosynthesis-inducing endoxylanase elicits electrolyte leakage and necrosis in Nicotiana tabacum cv. Xanthi leaves. Plant Physiol. 94:1849-1854.

Berrocal-Lobo, M., Molina, A., and Solano, R. 2002. Constitutive expression of ETHYLENE-RESPONSE-FACTOR1 in Arabidopsis confers resistance to several necrotrophic fungi. Plant J. 29:23-32.

Bethke, G., Unthan, T., Uhrig, J. F., Pöschl, Y., Gust, A. A., Scheel, D., and Lee, J. 2009. Flg22 regulates the release of an ethylene response factor substrate from MAP kinase 6 in Arabidopsis thaliana via ethylene signaling. Proc. Natl. Acad. Sci. U.S.A. 106:8067-8072.

Brandwagt, B. F., Mesbah, L. A., Takken, F. L. W., Laurent, P. L., Kneppers, T. J. A., Hille, J., and Nijkamp, H. J. J. 2000. A longevity assurance gene homolog of tomato mediates resistance to Alternaria alternata $\mathrm{f}$. sp. lycopersici toxins and fumonisin B1. Proc. Natl. Acad. Sci. U.S.A. 97:4961-4966.

Brandwagt, B. F., Kneppers, T. J. A., Van der Weerden, G. M., Nijkamp, H. J. J., and Hille, J. 2001. Most AAL toxin-sensitive Nicotiana species are resistant to the tomato fungal pathogen Alternaria alternata $\mathrm{f}$. $\mathrm{sp}$. lycopersici. Mol. Plant-Microbe Interact. 14:460-470.

Brown, R. L., Kazan, K., McGrath, K. C., Maclean, D. J., and Manners, J. M. 2003. A role for the GCC-box in jasmonate-mediated activation of the PDF1.2 gene of Arabidopsis. Plant Physiol. 132:1020-1032.

Chang, C., Kwok, S. F., Bleecker, A. B., and Meyerowitz, E. M. 1993. Arabidopsis ethylene-response gene ETR1: Similarity of product to two-component regulators. Science 262:539-544

Choi du, S., Hwang, I. S., and Hwang, B. K. 2012. Requirement of the cytosolic interaction between PATHOGENESIS-RELATED PROTEIN10 and LEUCINE-RICH REPEAT PROTEIN1 for cell death and defense signaling in pepper. Plant Cell 24:1675-1690.

Doxey, A. C., Yaish, M. W., Moffatt, B. A., Griffith, M., and McConkey, B J. 2007. Functional divergence in the Arabidopsis beta-1,3-glucanase gene family inferred by phylogenetic reconstruction of expression states. Mol. Biol. Evol. 24:1045-1055.
Egusa, M., Ozawa, R., Takabayashi, J., Otani, H., and Kodama, M. 2009. The jasmonate signaling pathway in tomato regulates susceptibility to a toxin-dependent necrotrophic pathogen. Planta 229:965-976.

Egusa, M., Miwa, T., Kaminaka, H., Takano, Y., and Kodama, M. 2013. Nonhost resistance of Arabidopsis thaliana against Alternaria alternata involves both pre- and post invasive defenses but is collapsed by AALtoxin in the absence of $\mathrm{LOH} 2$. Phytopathology 103:733-740.

Fischer, U., and Dröge-Laser, W. 2004. Overexpression of NtERF5, a new member of the tobacco ethylene response transcription factor family enhances resistance to tobacco mosaic virus. Mol. Plant-Microbe Interact. 17:1162-1171.

Fujimoto, S. Y., Ohta, M., Usui, A., Shinshi, H., and Ohme-Takagi, M. 2000. Arabidopsis ethylene-responsive element binding factors act as transcriptional activators or repressors of GCC box-mediated gene expression. Plant Cell 12:393-404.

Gagne, J. M., Smalle, J., Gingerich, D. J., Walker, J. M., Yoo, S. D. Yanagisawa, S., and Vierstra, R. D. 2004. Arabidopsis EIN3-binding Fbox 1 and 2 form ubiquitin-protein ligases that repress ethylene action and promote growth by directing EIN3 degradation. Proc. Natl. Acad. Sci. U.S.A. 101:6803-6808.

Gechev, T. S., Gadjev, I. Z., and Hille, J. 2004, An extensive microarray analysis of AAL-toxin-induced cell death in Arabidopsis thaliana brings new insights into the complexity of programmed cell death in plants. Cell. Mol. Life Sci. 61:1185-1197.

Gilchrist, D. G. 1997. Mycotoxins reveal connections between plants and animals in apoptosis and ceramide signaling. Cell Death Differ. 4:689698.

Gilchrist, D. G. 1998. Programmed cell death in plant disease: The purpose and promise of cellular suicide. Annu. Rev. Phytopathol. 36:393414.

Glazebrook, J. 2005. Contrasting mechanisms of defense against biotrophic andnecrotrophic pathogens. Annu. Rev. Phytopathol. 43:205227.

Greenberg, J. T. 1997. Programmed cell death in plant-pathogen interactions. Annu. Rev. Plant Physiol. Plant Mol. Biol. 48:525-545.

Greenberg, J. T., and Yao, N. 2004. The role and regulation of programmed cell death in plant-pathogen interactions. Cell Microbiol. 6:201-211.

Guo, H., and Ecker, J. R. 2003. Plant responses to ethylene gas are mediated by $\mathrm{SCF}^{\mathrm{EBF} 1 / \mathrm{EBF} 2}$-dependent proteolysis of EIN3 transcription factor. Cell 115:667-677.

Hamamouch, N., Li, C., Hewezi, T., Baum, T. J., Mitchum, M. G., Hussey, R. S., Vodkin, L. O., and Davis, E. L. 2012. The interaction of the novel $30 \mathrm{C} 02$ cyst nematode effector protein with a plant $\beta$-1,3-endoglucanase may suppress host defence to promote parasitism. J. Exp. Bot. 63:36833695.

Hellens, R. P., Edwards, E. A., Leyland, N. R., Bean, S., and Mullineaux, P. M. 2000. pGreen: A versatile and flexible binary Ti vector for Agrobacterium-mediated plant transformation. Plant Mol. Biol. 42:819-832.

Hibi, T., Kosugi, S., Iwai, T., Kawata, M., Seo, S., Mitsuhara, I., and Ohashi, Y. 2007. Involvement of EIN3 homologues in basic PR gene expression and flower development in tobacco plants. J. Exp. Bot. 58:3671-3678.

Ishihama, N., Yamada, R., Yoshioka, M., Katou, S., and Yoshioka, H. 2011. Phosphorylation of the Nicotiana benthamiana WRKY8 tran scription factor by MAPK functions in the defense response. Plant Cell 23:1153-1170.

Kamoun, S., Hamada, W., and Huitema, E. 2003. Agrosuppression: A bioassay for the hypersensitive response suited to high-throughput screening. Mol. Plant-Microbe Interact. 16:7-13.

Kosugi, S., and Ohashi, Y. 2000. Cloning and DNA-binding properties of a tobacco Ethylene-Insensitive3 (EIN3) homolog. Nucleic Acids Res. 28:960-967.

Lee, S.-W., Han, S.-W., Sririyanum, M., Park, C.-J., Seo, Y.-S., and Ronald, P. C. 2009. Type I-secreted, sulfated peptide triggers XA21mediated innate immunity. Science 326:850-853.

Lorang, J. M., Sweat, T. A., and Wolpert, T. J. 2007. Plant disease susceptibility conferred by a "resistance" gene. Proc. Natl. Acad. Sci. U.S.A 104:14861-14866.

Lorang, J., Kidarsa, T., Bradford, C. S., Gilbert, B., Curtis, M., Tzeng, S C., Maier, C. S., and Wolpert, T. J. 2012. Tricking the guard: Exploiting plant defense for disease susceptibility. Science 338:659-662.

Lorenzo, O., Piqueras, R., Sánchez-Serrano, J. J., and Solano, R. 2003. ETHYLENE RESPONSE FACTOR1 integrates signals from ethylene and jasmonate pathways in plant defense. Plant Cell 15:165-178.

Mahalingam, R., Gomez-Buitrago, A., Eckardt, N., Shah, N., GuevaraGarcia, A., Day, P., Raina, R., and Fedoroff, N. V. 2003. Characterizing the stress/defense transcriptome of Arabidopsis. Genome Biol. 4:R20.

Markham, J. E., and Hille, J. 2001. Host-selective toxins as agents of cell death in plant-fungus interactions. Mol. Plant Pathol. 2:229-239.

Mase, K., Mizuno, T., Ishihama, N., Fujii, T., Mori, H., Kodama, M., and 
Yoshioka, H. 2012. Ethylene signaling pathway and MAPK cascades are required for AAL toxin-induced programmed cell death. Mol. PlantMicrobe Interact. 25:1015-1025.

McGrath, K. C., Dombrecht, B., Manners, J. M., Schenk, P. M., Edgar, C. I., Maclean, D. J., Scheible, W. R., Udvardi, M. K., and Kazan, K. 2005. Repressor- and activator-type ethylene response factors functioning in jasmonate signaling and disease resistance identified via a genome-wide screen of Arabidopsis transcription factor gene expression. Plant Physiol. 139:949-959.

Moffat, C. S., Ingle, R. A., Wathugala, D. L., Saunders, N. J., Knight, H., and Knight, M. R. 2012. ERF5 and ERF6 play redundant roles as positive regulators of JA/Et-mediated defense against Botrytis cinerea in Arabidopsis. PLoS One 7:e35995.

Moffett, P. 2009. Mechanisms of recognition in dominant $R$ gene mediated resistance. Adv. Virus Res. 75:1-33.

Moore, T., Martineau, B., Bostock, R. M., Lincoln, J. E., and Gilchrist, D. G. 1999. Molecular and genetic characterization of ethylene involvement in mycotoxin-induced plant cell death. Physiol. Mol. Plant Pathol. 54:73-85.

Moussatos, V. V., Yang, S. F., Ward, B., and Gilchrist, D. G. 1994. AALtoxin induced physiological changes in Lycopersicon esculentum Mill: Roles for ethylene and pyrimidine intermediates in necrosis. Physiol. Mol. Plant Pathol. 44:455-468.

Mukherjee, A. K., Carp, M. J., Zuchman, R., Ziv, T., Horwitz, B. A., and Gepstein, S. 2010. Proteomics of the response of Arabidopsis thaliana to infection with Alternaria brassicicola. J. Proteomics 73:709-720.

Nakagawa, T., Suzuki, T., Murata, S., Nakamura, S., Hino, T., Maeo, K., Tabata, R., Kawai, T., Tanaka, K., Niwa, Y., Watanabe, Y., Nakamura, K., Kimura, T., and Ishiguro, S. 2007. Improved Gateway binary vectors: High-performance vectors for creation of fusion constructs in transgenic analysis of plants. Biosci. Biotechnol. Biochem. 71:20952100 .

Nakano, T., Suzuki, K., Fujimura, T., and Shinshi, H. 2006. Genome-wide analysis of the ERF gene family in Arabidopsis and rice. Plant Physiol. 140:411-432.

Nasir, K. H., Takahashi, Y., Ito, A., Saitoh, H., Matsumura, H., Kanzaki, H., Shimizu, T., Ito, M., Fujisawa, S., Sharma, P. C., Ohme-Takagi, M., Kamoun, S., and Terauchi, R. 2005. High-throughput in planta expression screening identifies a class II ethylene-responsive element binding factor-like protein that regulates plant cell death and non-host resistance. Plant J. 43:491-505.

Navarre, D. A., and Wolpert, T. J. 1999. Victorin induction of an apoptotic/ senescence-like response in oats. Plant Cell 11:237-249.

Ogata, T., Kida, Y., Arai, T., Kishi, Y., Manago, Y., Murai, M., and Matsushita, Y. 2012. Overexpression of tobacco ethylene response factor NtERF3 gene and its homologues from tobacco and rice induces hypersensitive response-like cell death in tobacco. J. Gen. Plant Pathol. 78:8-17.

Ohme-Takagi, M., and Shinshi, H. 1995. Ethylene-inducible DNA binding proteins that interact with an ethylene-responsive element. Plant Cell 7:173-182.

Ohta, M., Matsui, K., Hiratsu, K., Shinshi, H., and Ohme-Takagi, M. 2001. Repression domains of class II ERF transcriptional repressors share an essential motif for active repression. Plant Cell 13:1959-1968.

Oñate-Sánchez, L., Anderson, J. P., Young, J., and Singh, K. B. 2007. AtERF14, a member of the ERF family of transcription factors, plays a nonredundant role in plant defense. Plant Physiol. 143:400-409.

Potuschak, T., Lechner, E., Parmentier, Y., Yanagisawa, S., Grava, S., Koncz, C., and Genschik, P. 2003. EIN3-dependent regulation of plan ethylene hormone signaling by two Arabidopsis F box proteins: EBF1 and EBF2. Cell 115:679-689.

Pré, M., Atallah, M., Champion, A., De Vos, M., Pieterse, C. M., and Memelink, J. 2008. The AP2/ERF domain transcription factor ORA59 integrates jasmonic acid and ethylene signals in plant defense. Plant Physiol. 147:1347-1357.

Ratcliff, F., Martin-Hernandez, A. M., and Baulcombe, D. C. 2001. Tobacco rattle virus as a vector for analysis of gene function by silencing. Plant J. 25:237-245.

Riechmann, J. L., and Meyerowitz, E. M. 1998. The AP2/EREBP family of plant transcription factors. Biol. Chem. 379:633-646.

Rieu, I., Mariani, C., and Weterings, K. 2003. Expression analysis of five tobacco EIN3 family members in relation to tissue-specific ethylene responses. J. Exp. Bot. 54:2239-2244.

Roman, G., Lubarsky, B., Kieber, J. J., Rothenberg, M., and Ecker, J. R. 1995. Genetic analysis of ethylene signal transduction in Arabidopsis thaliana: Five novel mutant loci integrated into a stress response pathway. Genetics 139:1393-1409.

Sakuma, Y., Liu, Q., Dubouzet, J. G., Abe, H., Shinozaki, K., and Yamaguchi-Shinozaki, K. 2002. DNA-binding specificity of the ERF/AP2 domain of Arabidopsis DREBs, transcription factors involved in dehydration- and cold-inducible gene expression. Biochem. Biophys. Res. Commun. 290:998-1009.

Solano, R., Stepanova, A., Chao, Q., and Ecker, J. R. 1998. Nuclear events in ethylene signaling: A transcriptional cascade mediated by ETH YLENE-INSENSITIVE3 and ETHYLENE-RESPONSE-FACTOR1. Genes Dev. 12:3703-3714.

Son, G. H., Wan, J., Kim, H. J., Nguyen, X. C., Chung, W. S., Hong, J. C. and Stacey, G. 2012. Ethylene-responsive element-binding factor 5, ERF5, is involved in chitin-induced innate immunity response. Mol. Plant-Microbe Interact. 25:48-60.

Spassieva, S. D., Markham, J. E., and Hille, J. 2002. The plant disease resistance gene Asc-1 prevents disruption of sphingolipid metabolism during AAL-toxin-induced programmed cell death. Plant J. 32:561-572.

Sweat, T. A., and Wolpert, T. J. 2007. Thioredoxin $h 5$ is required for victorin sensitivity mediated by a CC-NBS-LRR gene in Arabidopsis. Plant Cell 19:673-687.

Ternes, P., Feussner, K., Werner, S., Lerche, J., Iven, T., Heilmann, I., Riezman, H., and Feussner, I. 2011. Disruption of the ceramide synthase LOH1 causes spontaneous cell death in Arabidopsis thaliana. New Phytol. 192:841-854.

Verhage, A., van Wees, S. C., and Pieterse, C. M. 2010. Plant immunity: It's the hormones talking, but what do they say? Plant Physiol. 154:536540.

Walton, J. D. 1996. Host-selective toxins: Agents of compatibility. Plant Cell 8:1723-1733.

Wang, H., Li, J., Bostock, R. M., and Gilchrist, D. G. 1996. Apoptosis: A functional paradigm for programmed plant cell death induced by a hostselective phytotoxin and invoked during development. Plant Cell 8:375391.

Wolpert, T. J., Macko, V., Acklin, W., Jaun, B., Seibl, J., Meili, J., and Arigoni, D. 1985. Structure of victorin C, the major host-selective toxin from Cochliobolus victoriae. Experientia 41:1524-1529.

Yanagisawa, S., Yoo, S.-D., and Sheen, J. 2003. Differential regulation of EIN3 stability by glucose and ethylene signalling in plants. Nature 425:521-525

Zhang, L., Jia, C., Liu, L., Zhang, Z., Li, C., and Wang, Q. 2011. The involvement of jasmonates and ethylene in Alternaria alternata $\mathrm{f} . \mathrm{sp}$ lycopersici toxin-induced tomato cell death. J. Exp. Bot. 62:5405-5418. 